\title{
Endocrine neoplasms in familial syndromes of hyperparathyroidism
}

\author{
Yulong Li and William F Simonds \\ Metabolic Diseases Branch, National Institute of Diabetes and Digestive and Kidney Diseases,
} National Institutes of Health, Bethesda, Maryland, USA

Correspondence should be addressed to W F Simonds Email wfs@helix.nih.gov

\begin{abstract}
Familial syndromes of hyperparathyroidism, including multiple endocrine neoplasia type 1 (MEN1), multiple endocrine neoplasia type 2A (MEN2A), and the hyperparathyroidism-jaw tumor (HPT-JT), comprise $2-5 \%$ of primary hyperparathyroidism cases. Familial syndromes of hyperparathyroidism are also associated with a range of endocrine and nonendocrine tumors, including potential malignancies. Complications of the associated neoplasms are the major causes of morbidities and mortalities in these familial syndromes, e.g., parathyroid carcinoma in HPT-JT syndrome; thymic, bronchial, and enteropancreatic neuroendocrine tumors in MEN1; and medullary thyroid cancer and pheochromocytoma in MEN2A. Because of the different underlying mechanisms of neoplasia, these familial tumors may have different characteristics compared with their sporadic counterparts. Large-scale clinical trials are frequently lacking due to the rarity of these diseases. With technological advances and the development of new medications, the natural history, diagnosis, and management of these syndromes are also evolving. In this article, we summarize the recent knowledge on endocrine neoplasms in three familial hyperparathyroidism syndromes, with an emphasis on disease characteristics, molecular pathogenesis, recent developments in biochemical and radiological evaluation, and expert opinions on surgical and medical therapies. Because these familial hyperparathyroidism syndromes are associated with a wide variety of tumors in different organs, this review is focused on those endocrine neoplasms with malignant potential.
\end{abstract}

\author{
Key Words \\ - multiple endocrine \\ neoplasia type 1 (MEN1) \\ - multiple endocrine \\ neoplasia type $2 \mathrm{~A}$ \\ (MEN2A) \\ - hyperparathyroidism-jaw \\ tumor (HPT-JT) \\ - malignant tumor \\ - neuroendocrine tumor
}

\section{Introduction}

Primary hyperparathyroidism has an estimated prevalence of $0.1 \%$ in the United States. Familial forms represent some $2-5 \%$ of primary hyperparathyroidism and are caused by germline genetic mutations (Table 1). Among these, multiple endocrine neoplasia type 1 (MEN1), multiple endocrine neoplasia type 2A (MEN2A), and the hyperparathyroidism-jaw tumor syndrome (HPT-JT) are familial syndromes of hyperparathyroidism that are associated with a spectrum of endocrine tumors and other malignancies. Some of these familial endocrine tumors behave very differently from their sporadic counterparts, showing distinct clinical characteristics and disease courses. Many of these tumors also have a significant malignant potential and require different treatment approaches. Being familiar with their unique features and natural history may facilitate diagnosis and help to establish individualized management to improve outcomes.

Published by Bioscientifica Ltd 
Table 1 Familial causes of hyperparathyroidism.

\begin{tabular}{|c|c|c|c|}
\hline Disorder & $\begin{array}{l}\text { Germline gene } \\
\text { mutation }\end{array}$ & $\begin{array}{l}\text { Molecular } \\
\text { pathology }\end{array}$ & Endocrine neoplasms with malignant potential \\
\hline \multicolumn{4}{|c|}{ Familial syndromes leading to primary hyperparathyroidism and including endocrine tumors with malignant potential } \\
\hline Multiple endocrine neoplasia type 1 syndrome & MEN1 & Loss of function & $\begin{array}{l}\text { Malignant duodenopancreatic } \\
\text { neuroendocrine tumor; thymic and } \\
\text { bronchial neuroendocrine tumors }\end{array}$ \\
\hline $\begin{array}{l}\text { Multiple endocrine neoplasia type 2A } \\
\text { syndrome }\end{array}$ & RET & Gain of function & $\begin{array}{l}\text { Medullary thyroid cancer; malignant } \\
\text { pheochromocytoma }\end{array}$ \\
\hline Hyperparathyroidism-jaw tumor syndrome & CDC73 & Loss of function & Parathyroid carcinoma \\
\hline \multicolumn{4}{|c|}{ Familial disorders leading to primary hyperparathyroidism only } \\
\hline Familial hypocalciuric hypercalcemia & CASR & Loss of function & Not applicable \\
\hline Neonatal severe primary hyperparathyroidism & CASR & Loss of function & Not applicable \\
\hline $\begin{array}{l}\text { Familial isolated hyperparathyroidism } \\
\text { (CDC73, MEN1, CASR mutation testing } \\
\text { negative) }\end{array}$ & Unknown & Unknown & Not applicable \\
\hline
\end{tabular}

We herein summarize and update the knowledge on endocrine neoplasms with malignant potential found in familial syndromes of hyperparathyroidism, including 1) HPT-JT-associated parathyroid carcinoma; 2) MEN1associated nonfunctioning pancreatic neuroendocrine tumors (pNETs), gastrinoma and insulinoma, and thymic and bronchial NET (sometimes referred to as 'carcinoid tumors'); and 3) MEN2A-associated medullary thyroid cancer and pheochromocytoma. Because of space limitations, we favor the citation of recent review articles, wherein the curious reader can easily find reference to the original studies.

\section{Parathyroid cancer in the hyperparathyroidism- jaw tumor syndrome}

HPT-JT is an autosomal-dominant familial cancer syndrome caused by inactivating germline mutation of the cell division cycle 73 (CDC73) gene (formerly called HRPT2), with incomplete penetrance and variable expression (Carpten et al. 2002, Bradley et al. 2006). Because of its incomplete penetrance, patients with germline CDC73 mutation can present with a spectrum of phenotypes including seemingly sporadic parathyroid cancer, familial isolated hyperparathyroidism (FIHP) with or without parathyroid cancer, or full expression of HPT-JT (Sharretts \& Simonds 2010). Patients with HPT-JT may manifest hyperparathyroidism and other medical conditions, including fibro-osseous tumors of the maxilla or mandible (histologically classified as cemento-ossifying fibromas), kidney tumors, and uterine lesions. Hypercalcemia and its complications (such as nephrolithiasis) and bone disease are major causes of mortality and morbidity in primary hyperparathyroidism. Patients of HPT-JT also have an increased risk of developing parathyroid carcinoma, ranging from 15 to $37.5 \%$ in different case series (Sharretts \& Simonds 2010, Mehta et al. 2014). For comparison, parathyroid carcinoma only accounts for $0.005 \%$ of total cancer cases in National Cancer Database Report (Hundahl et al. 1999). Interestingly, somatic inactivating CDC73 mutations are strongly implicated in sporadic parathyroid carcinoma and have been found in up to $70 \%$ of such cancers (Shattuck et al. 2003, Do Cao et al. 2015).

HPT-JT is an extremely rare disease. The available literature includes only case reports, case series, and retrospective studies of small sample size. The prevalence of this disease in general population is unknown. Cases of HPT-JT have been reported in Australia, the US, Canada, Europe, Japan, India, China, Thailand, and France (Howell et al. 2003, Bricaire et al. 2013, Kutcher et al. 2013, Kong et al. 2014, Sriphrapradang et al. 2014, Khadilkar et al. 2015, Mathews et al. 2015, Shibata et al. 2015), suggesting that this disease has neither ethnic preference. No gender preference was found in a large patient cohort (Asare et al. 2015).

\section{Clinical manifestations}

The vast majority of parathyroid carcinomas are functioning tumors that cause clinical symptoms or signs related to severe primary hyperparathyroidism and hypercalcemia, such as bone or joint pain, fatigue, nephrolithiasis, muscle weakness, constipation, reduced bone mass, and psychiatric abnormalities. Distinct from primary hyperparathyroidism due to parathyroid adenoma, patients with parathyroid cancer (either sporadic or in the context of HPT-JT or FIHP) usually present with higher calcium levels and more severe symptoms (Shane 2001, Wei \& Harari 2012). Total serum calcium levels are usually more than $13 \mathrm{mg} / \mathrm{dL}$ and may be even higher than

Published by Bioscientifica Ltd. 
$16 \mathrm{mg} / \mathrm{dL}$, with parathyroid hormone levels at least three to ten times of the upper normal limit and often in the range 200-1800 pg/mL (Wei \& Harari 2012, Mehta et al. 2014, Sriphrapradang et al. 2014). Nonfunctioning parathyroid carcinoma has been reported in a normocalcemic CDC73 mutation carrier (Guarnieri et al. 2006). Patients with HPT-JT may also have or have had silent or clinically evident cemento-ossifying fibromas of the maxilla or mandible or uterine abnormalities.

Parathyroid carcinoma can cause compressive symptoms due to mass effect such as dysphagia, dyspnea, dysphonia, or dysarthria (Shane 2001, Wei \& Harari 2012). Parathyroid carcinomas are likely to be much bigger than parathyroid adenomas, with a diameter typically $2-3 \mathrm{~cm}$ or greater and a weight in the range 2-10g (Harari et al. 2011, Siu et al. 2011, Wei \& Harari 2012, Chiofalo et al. 2014, Asare et al. 2015). Because of their large size and frequently firm texture, parathyroid carcinomas can often be palpated on physical exam (Shane 2001, Wei \& Harari 2012). Patients with parathyroid carcinoma may also have complaints related to distant metastasis. The most common sites of metastasis include upper mediastinum, lung, pleura, and bone (Do Cao et al. 2015).

\section{Molecular pathophysiology}

The CDC73 gene encodes the 531 amino acid protein parafibromin (also known as protein CDC73 or CDC73p) (Carpten et al. 2002, Bradley et al. 2006). Parafibromin is a presumed tumor-suppressor protein because germlineinactivating mutation of the $C D C 73$ gene can result in full or partial expression of the clinical syndrome of HPT-JT. Parafibromin contains both nuclear and nucleolar localization signals (Dehghani et al. 2005, Hahn \& Marsh 2005, 2007, Bradley et al. 2007), and its C-terminal region bears significant homology to the C-terminal region of yeast protein Cdc73p (Newey et al. 2010). Like yeast Cdc73p, human parafibromin physically interacts with the components of the polymerase-associated factor 1 (PAF1) complex. The PAF1 complex plays a role in transcriptional regulation of RNA polymerase II (Newey et al. 2009, Jaehning 2010). In eukaryotes, parafibromin and the PAF1 complex play roles in the recruitment and activation of histone modification factors, transcriptional elongation, chromatin remodeling, and the recruitment of 3'-end processing factors necessary for accurate termination of transcription, such as cleavage and polyadenylation specificity factor (CPSF) and cleavage stimulation factor (CStF) (Jaehning 2010, Newey et al. 2010). Downregulation of parafibromin increases levels of c-Myc, a proto-oncogene, and established regulator of cell growth (Lin et al. 2008), and enhances expression of c-Myc target genes (Jaenicke et al. 2016). Despite this knowledge of the cellular functions of parafibromin, our understanding of the necessary links between the loss of parafibromin function and the development of parathyroid cancer remains incomplete.

\section{Diagnosis}

When a patient presents with severe symptomatology of primary hyperparathyroidism and significantly elevated serum calcium and parathyroid hormone levels, it should trigger a high index of suspicion for parathyroid cancer and possible germline CDC73 mutation. Such a presentation should prompt careful elaboration of the family medical history for benign or malignant parathyroid disease and/or fibro-osseous jaw tumors. In patients with suspected or proven parathyroid cancer, genetic investigation for germline CDC73 mutation and jaw imaging should be considered to rule out HPT-JT. Besides CDC73 mutations that can be detected by conventional mutational analysis, intragenic deletion of $C D C 73$ has also been reported in patients with familial hyperparathyroidism and parathyroid carcinoma (Korpi-Hyovalti et al. 2014). In a French cohort, one-third of patients were found to have germline gross deletion of CDC73 gene (Bricaire et al. 2013). Therefore, intragenic and gross gene deletion should be assessed as a part of genetic analysis in patients with a high index of suspicion but negative $C D C 73$ mutational testing. Partial or complete gene deletion can be detected by methods such as exon array comparative genome hybridization. Patients with parathyroid carcinoma have a high risk of lymph node (15-30\%) and distal metastasis (33\%) at their initial presentation (Wei \& Harari 2012). Therefore, multiple imaging modalities are recommended in the initial workup.

No single radiological modality has sufficient sensitivity and specificity for localization of parathyroid carcinoma. In one series, technetium-99m sestamibi scanning made the correct localization in only $46.2 \%$ cases (Mehta et al. 2014). In another series, the sensitivity of sestamibi scan and ultrasonography for parathyroid carcinoma were 79 and 69\%, respectively (Kebebew et al. 2001). The combination of sestamibi scan and neck ultrasound is recommended in the initial workup (Wei \& Harari 2012) (Fig. 1). On ultrasound, parathyroid carcinoma is typically found as a solid mass posterior to the thyroid gland. Compared with benign parathyroid lesions, on ultrasound, parathyroid carcinomas usually appear larger, more hypoechoic, hypervascular, heterogeneous, lobulated with irregular

Published by Bioscientifica Ltd 

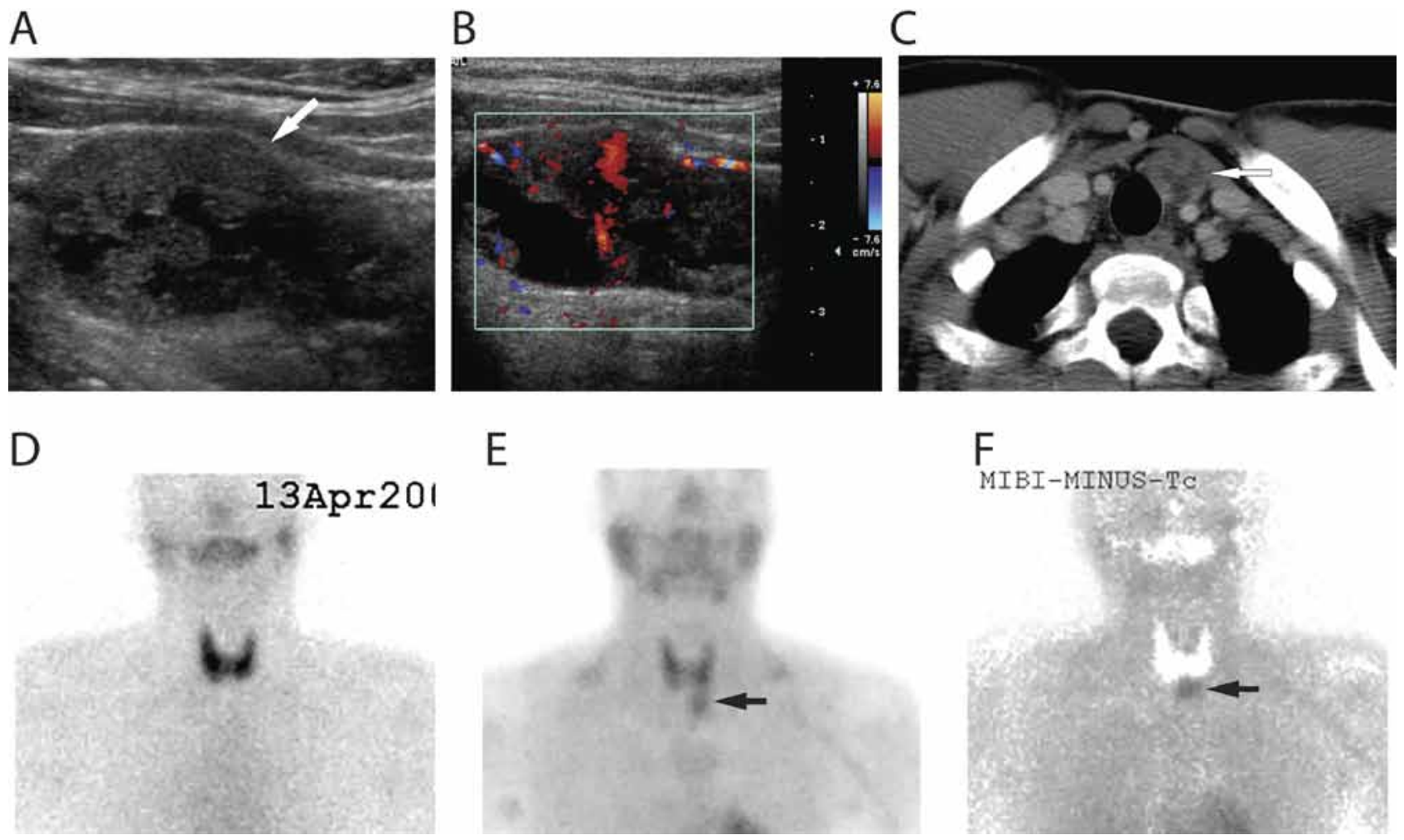

Figure 1

Preoperative images of a parathyroid carcinoma located in the inferior anterior left neck of an HPT-JT patient. (A) Ultrasonographic left longitudinal view showed a large $3.5 \times 2 \mathrm{~cm}$, hypoechoic, and heterogeneous lesion with irregular border suspicious for parathyroid carcinoma (arrow). (B) Doppler image showed that the lesion is hypervascular. (C) Neck CT image showed a heterogeneous mass lesion, marked by the arrow, with internal cystic/ necrotic changes located inferiorly to the left lower pole of the thyroid gland. (D) Technetium- $99 \mathrm{~m}$ pertechnetate scan of the neck showed normal appearing thyroid glands. (E) Sestamibi scan of the neck showed an area of excess increased uptake seen just below the left lobe of the thyroid (arrow) (F) Sestamibi-technetium subtraction image showed an increased uptake in a parathyroid lesion that was later proven to be a parathyroid carcinoma by surgical pathology (arrow).

borders, and are associated with a higher depth/width ratio and infiltration into surrounding tissues (Hara et al. 2001, Sidhu et al. 2011, Do Cao et al. 2015).

When sestamibi scan is negative, thin-cut CT may be helpful in localizing disease (Harari et al. 2008). In patients with locally advanced or metastatic parathyroid carcinoma, CT or MRI of the neck/mediastinum/chest/abdomen, technetium bone scan, and 18F-fluorodeoxyglucose PET/CT scanning can all be used as a part of metastasis and recurrence workup (Wei \& Harari 2012, Do Cao et al. 2015).

Parathyroid biopsy is not recommended as an initial step to establish the diagnosis if parathyroid cancer is suspected, due to possibility of tumor rupture and seeding. In addition, it is technically difficult to differentiate benign from malignant tumor in histopathology exam using the small sample obtained through fine-needle biopsy. Misdiagnosis and confusion between parathyroid carcinoma and Hürthle cell thyroid lesion have been reported (Sriphrapradang et al. 2014). However, in patients with metastatic tumors, when seeding is of less concern, biopsy of metastatic lesions can help establish the diagnosis by histological examination and determination of the parathyroid hormone level in the aspirated tissue (Harari et al. 2011).

Upon surgical pathologic review, certain features, including fibrous bands forming trabecular architecture, capsular invasion, vascular or lymph node invasion, and increased mitotic activity and aneuploidy, are strongly indicative of parathyroid carcinoma (Schantz \& Castleman 1973, Gao et al. 2010). Immunohistochemical staining of parathyroid carcinoma is typically positive for chromogranin A and PTH, and negative for neuropeptide, calcitonin, and thyroglobulin (Sriphrapradang et al. 2014). A recent study of 24 parathyroid cancers and 14 benign adenomas provided evidence that employment of an immunohistochemical panel has better sensitivity and specificity than any single marker to diagnose parathyroid cancer, when used in conjunction with

Published by Bioscientifica Ltd. 
classical histopathology (Truran et al. 2014). For instance, immunohistochemical analysis of parathyroid cancers usually demonstrates positive staining for PGP9.5, galectin-3, and Ki-67, but negative staining for nuclear parafibromin (Truran et al. 2014).

\section{Management}

Proper screening for HPT-JT-associated tumors is recommended to start at age 5-10 in asymptomatic patients with germline CDC73 gene mutation found through genetic testing (Pichardo-Lowden et al. 2011, Jackson et al. 2015). Screening includes biochemical testing every 6-12 months, and panoramic dental imaging and renal ultrasound every 5 years (Jackson et al. 2015). The follow-up schedule should be individualized. First-degree relatives of patients with parathyroid cancer or HPT-JT should also be genetically screened for $C D C 73$ mutation (when mutation is known) or periodically screened for primary hyperparathyroidism.

Surgery is the primary treatment modality for parathyroid carcinoma. In general, patients should be treated in specialized centers with a high volume of endocrine surgical cases. Primary parathyroid carcinoma should be removed by en bloc resection. Due to the high recurrence rate of hyperparathyroidism (about 20\%) in HPT-JT patients, some experts recommend en bloc resection of parathyroid tumors with bilateral neck exploration (Mehta et al. 2014). Other authors recommend ipsilateral thyroidectomy and complete central neck dissection for malignant tumors (Pichardo-Lowden et al. 2011), or use of radiological evidence of multiglandular involvement to guide subtotal parathyroidectomy and/or bilateral neck exploration (Haciyanli et al. 2011, Pichardo-Lowden et al. 2011). For initial surgery, we would recommend en bloc resection for a lesion highly suspicious for parathyroid carcinoma, with strong consideration for bilateral neck exploration guided by radiological findings for other candidate lesions. The risk of nerve injury or other potential surgical complications must be weighed against the risk of recurrence and the likelihood of achieving surgical remission.

After the initial surgery, remission is defined as maintaining normal serum calcium and PTH level for more than 6 months, persistent disease as the return of hypercalcemia within 6 months of operation, and recurrence disease as recurrent hypercalcemia following 6 months of normocalcemia (Mehta et al. 2014).

The calcimimetic cinacalcet can be used in parathyroid carcinoma patients as a palliative or therapeutic treatment for hypercalcemia. Using the dose ranging from $30 \mathrm{mg}$ twice daily to $90 \mathrm{mg}$ four times daily, the greatest reduction inhypercalcemia were observed in patients with higher calcium levels (Silverberg et al. 2007).

The U.S. Food and Drug Administration approved denosumab in 2010 for osteoporosis in postmenopausal women, as well as for prevention/treatment of skeletonrelated events in patients with bone metastasis from solid tumors. Denosumab binds to and inhibits the receptor activator of nuclear factor kappa-B ligand (RANKL) and is a potent inhibitor of bone resorption. There is no clinical trial that has studied the efficacy and risk of denosumab in patients with parathyroid carcinoma. Several case reports found that denosumab led to successful control of hypercalcemia in patients with advanced parathyroid cancer and intractable hypercalcemia, but long-term follow-up is still lacking (Bowyer et al. 2013, Karuppiah et al. 2014, Jumpertz von Schwartzenberg et al. 2015).

Parathyroid carcinoma is not sensitive to radiation therapy or chemotherapy. Successful immunotherapy using intradermal injection of immunogenic peptides to stimulate antibodies against endogenous PTH has been reported (Betea et al. 2004, Horie et al. 2010), but clinical trials are lacking and its risks and efficacy still need to be further tested.

\section{Prognosis}

Median overall survival of HPT-JT patients ranges from 8.9 years (Mehta et al. 2014) to 14.3 years (Harari et al. 2011) from the date of diagnosis. Based on a retrospective review from 1985 to 2006 in a national cancer database, the 5- and 10-year relative survival rates of parathyroid carcinoma were 82.3 and 66\%, respectively (Asare et al. 2015). Several risk factors, including large tumor size, older age at diagnosis, and male gender, are associated with shorter survival. By contrast, lymph node status or radical parathyroid surgery was not found to be significant in predicting survival (Asare et al. 2015). Approximately, $50 \%$ of parathyroid carcinoma patients developed persistent or recurrent disease (Wei \& Harari 2012). The 5 -year survival rate after recurrence was only about 50\% (Silverberg et al. 2007), compared with $82.3 \%$ in all parathyroid carcinoma cases.

\section{Nonfunctioning pancreatic neuroendocrine tumors in MEN1}

MEN1 is a rare autosomal-dominant familial cancer syndrome caused by germline loss-of-function mutation of the MEN1 tumor-suppressor gene (Marx et al. 1999).

Published by Bioscientifica Ltd 
The syndrome is characterized by a predisposition to endocrine tumors in pituitary, parathyroid, and enteropancreatic endocrine cells, although tumors in several other endocrine and nonendocrine tissues are also associated with the syndrome (Schussheim et al. 2001). The common malignancies in MEN1 include functional and nonfunctional enteropancreatic neuroendocrine tumors, as well as thymic and bronchial NETs.

Pancreatic neuroendocrine tumors (pNETs) are clinically evident in $30-75 \%$ of MEN1 patients and present in $80-100 \%$ at postmortem examination, exhibiting an age-dependent penetrance (Goudet et al. 2010, Norton et al. 2015). In MEN1, the prevalence of nonfunctioning pNET is much higher than functioning pNET such as gastrinoma, insulinoma, and glucagonoma (Table 2) (Yates et al. 2015). The penetrance of nonfunctioning pNET is $34 \%$ at age 50, establishing it as the most frequent enteropancreatic tumor in MEN 1 patients (Triponez et al. 2006).

The natural history of MEN1 has been significantly impacted by the changes in the epidemiology of pNET over the past decade. Studies in France and the US have shown that the causes of death in MEN1 have shifted from functioning pNET to nonfunctioning malignant pNET and thymic tumors (Goudet et al. 2010, Ito et al. 2013a). The 5- and 10-year survival rates for nonfunctioning pNET are 75 and 50\%, compared with functioning pNET, which are 90 and 85\% (Jensen et al. 2008). The median overall survival is significantly longer for MEN1 patients with functioning pNET versus those with nonfunctioning tumors (Kouvaraki et al. 2006).

\section{Clinical features}

Nonfunctioning pNET may be clinically silent in MEN1 patients and detected only by abdominal imaging. Symptoms of malignant nonfunctioning pNET are related to local invasion, lymph node involvement, and distant metastases. Common locations for metastasis include liver (67\%), lymph node (14\%), and lung (10\%) (Triponez et al. 2006).

\section{Molecular pathophysiology}

The human MEN1 gene encodes the ubiquitously expressed 610 amino acid protein menin (Chandrasekharappa et al. 1997). Because germline frameshift, nonsense, missense, and deletion mutations in MEN1 expected to cause loss-of-function result in the clinical syndrome of MEN1, it is operationally a tumor suppressor. The menin protein contains multiple nuclear localization signals and can function as an epigenetic activator or repressor of gene transcription in different cellular contexts through interaction with distinct chromatin-modifying protein complexes (Yates et al. 2015). The crystal structure of human menin has been solved and supports its role as a scaffolding protein that can have opposite effects on transcription (Huang et al. 2012).

Menin interacts with a number of proteins that are involved in transcriptional regulation, genome stability, cell division, and cellular proliferation. These proteins include the transcriptional regulators c-Jun and JunD, members of the NF- $\mathrm{kB}$ family of transcription factors, SMAD family transcription factors including SMAD3 and the bone morphogenetic protein-2-regulated SMAD1 and SMAD5, the osteoblast regulator RUNX2, and the forkhead transcription factor FOXN3 (CHES1) involved in the DNA damage response (Yates et al. 2015). Despite these molecular insights, an understanding of the critical links between the loss of such protein-protein interactions in MEN1 and tumorigenesis in susceptible neuroendocrine cells is lacking.

\section{Diagnosis}

The mean time from the diagnosis of MEN1 to recognition of nonfunctioning pNET is about 5 years (Triponez et al. 2006). Both CT and MRI have relatively high sensitivity (81 and $88 \%$, respectively) for the detection of pNET, with excellent specificity and positive predictive values. Endoscopic ultrasound (EUS) is the most sensitive (close to $100 \%$ ) imaging modality for pNET, and can detect lesions as small as $0.3 \mathrm{~cm}$ as well as lymph node metastases (Yates et al. 2015). Because of its high sensitivity, some authors recommend the inclusion of EUS in baseline screening and follow-up surveillance of nonfunctioning pNET (Tonelli 2014). Its limitations include poor visualization of distal pancreatic lesions and being highly operator-dependent. Both ${ }^{111}$ indium- and ${ }^{68}$ gallium-based somatostatin receptor scintigraphy PET/CT can facilitate tumor staging, but have limited availability and radiation exposure risk (Yates et al. 2015). In a recent study of MEN1 patients, ${ }^{68} \mathrm{Ga}$-DOTATATE PET/CT has been reported to show no better sensitivity or specificity in detecting MEN1-related tumors (including pNET) than combined conventional imaging that included invasive endoscopic ultrasound (Lastoria et al. 2015). However, a larger study, comparing only noninvasive imaging modalities, demonstrated a clear superiority of ${ }^{68} \mathrm{Ga}$-DOTATATE PET/CT over conventional octreotide scintigraphy and CT for the detection of primary and

Published by Bioscientifica Ltd 


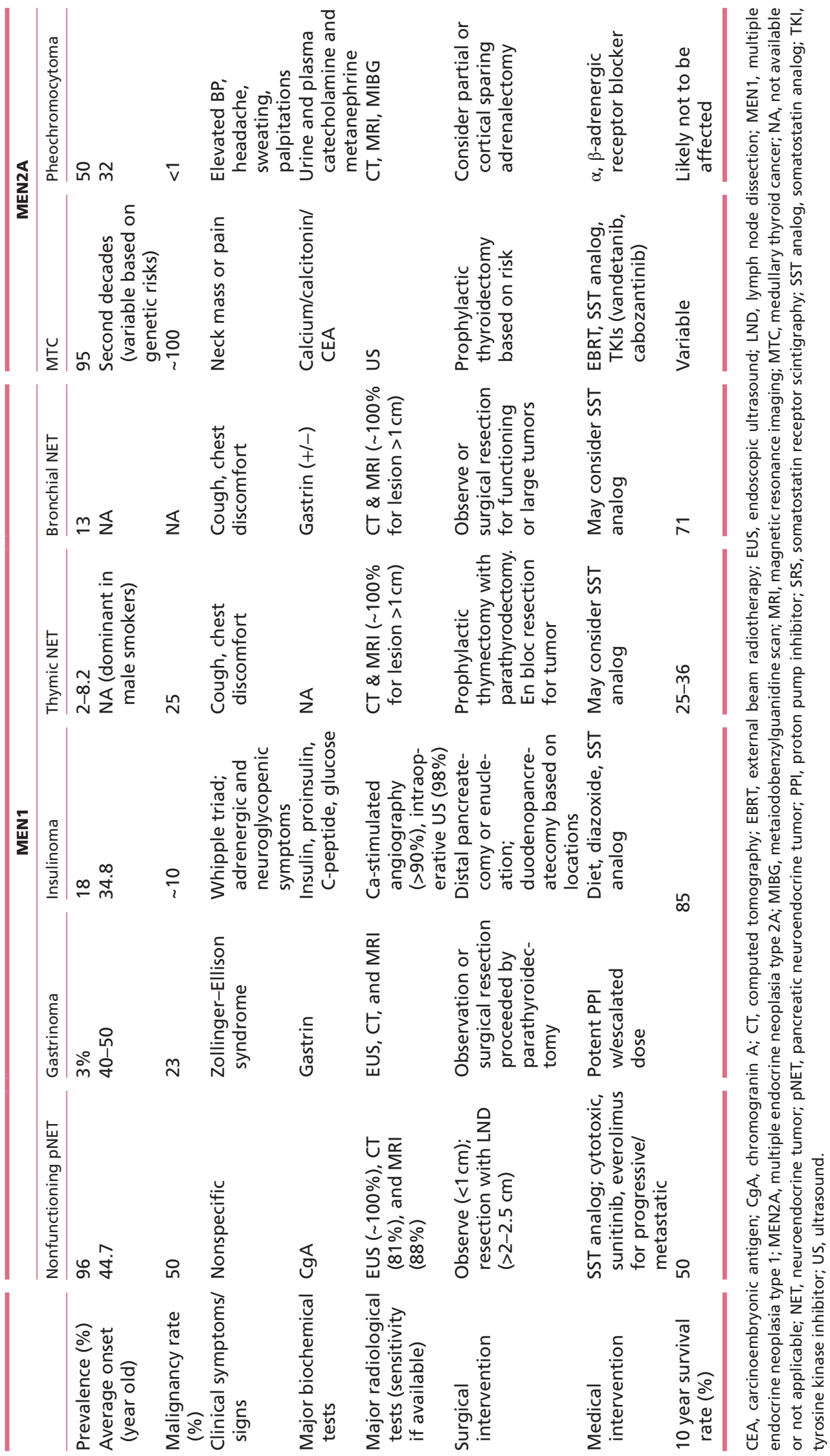


secondary neuroendocrine tumors, including pNET, in MEN1 patients (Sadowski et al. 2015).

The utility and accuracy of circulating tumor markers for the early recognition and diagnosis of nonfunctioning pNET is generally poor. For instance, the sensitivity of chromogranin A ( CgA) to diagnose pNET was only 0.33 (de Laat et al. 2013). However, if $\mathrm{CgA}$ is elevated at diagnosis, it can be used to evaluate treatment efficacy over time in advanced cases (Kunz et al. 2013). Interestingly, fasting serum pancreatic polypeptide levels, but not CgA or gastrin, correlated significantly with the number of primary and metastatic lesions detected by ${ }^{68} \mathrm{Ga}$-DOTATATE PET/CT in a recent study of neuroendocrine tumors in MEN1 patients; however, no pNET-specific analysis was reported (Sadowski et al. 2015). No urinary markers have yet proven useful for the early recognition and diagnosis of nonfunctioning pNET.

Pathological staging is essential before initiation of systemic therapy for pNET, because treatment algorithms for well-differentiated and poorly differentiated pNET are different (Kunz et al. 2013). The risk of malignancy significantly increases with tumor size (Tonelli 2014). Besides tumor size, Ki-67 index and mitotic rate are critical determinants for assessing prognosis. The latter two factors are used to assign tumor grade during pathologic examination of pNET. When the mitotic rate and Ki-67 index are discordant, the higher grade is assigned (Kunz et al. 2013). Immunohistochemical staining for CgA and synaptophysin is recommended.

\section{Treatment}

Typically nonfunctioning pNETs can be observed in asymptomatic MEN1 patients with low tumor burden or tumor size less than $1 \mathrm{~cm}$. Some authors recommended surgical intervention for nonfunctioning pNET greater than $1 \mathrm{~cm}$ due to their potential risk of hepatic metastasis (Imamura 2010, Machado 2012). Other experts, however, recognizing the significant mortality and morbidity of pancreatic surgery on one hand and the low risk of metastasis and death in MEN1 patients with nonfunctioning pNETs $<2 \mathrm{~cm}$ on the other hand, recommend reserving surgery for rapidly growing tumors or those tumors $>2 \mathrm{~cm}$ (Triponez et al. 2006). Enucleation or surgical resection with adjacent lymph node dissection can be considered for lesions larger than 2 or $2.5 \mathrm{~cm}$ (Kunz et al. 2013). Pancreaticoduodenectomy and distal pancreatectomy should be reserved for a small number of patients because of high risk of developing exocrine and endocrine pancreas insufficiency and increased morbidity (Bartsch et al. 2013, Vezzosi et al. 2015).

In patients with metastatic nonfunctioning pNET, resection of the primary tumor was associated with better survival (Keutgen et al. 2016). Resection of single or even multiple surgically amenable hepatic metastatic lesions is recommended by some and can sometimes be curative (Machado 2012). Radiofrequency ablation and transarterial chemoembolization can be used to control tumor burden or to treat lesions deep in the hepatic parenchyma (Imamura 2010, Kunz et al. 2013).

Well-differentiated NET in MEN1 usually responds poorly to platinum-based cytotoxic chemotherapy. Streptozocin, 5-flurouracil, or temozolomide can be considered in advanced, poorly differentiated pNET for palliative purposes (Kunz et al. 2013). The FDA has approved sunitinib and everolimus for the treatment of progressive metastatic pNET based on positive results from phase III clinical trials. Sunitinib inhibits VEGF receptor signaling. In phase III clinical trials in advanced pNET patients, sunitinib delayed the progression of pNET by 6 months and had a favorable adverse events profile (Raymond et al. 2011). Everolimus inhibits the mTOR pathway signaling. In the RADIANT-3 study, everolimus improved progression-free survival from 4.6 months in the placebo arm to 11 months in the treatment arm (Yao et al. 2011).

Poorly differentiated pNET may be treated by chemotherapy with platinum-based regimen (cisplatin/ carboplatin and etoposide for 4-6 cycles). For patients who relapse more than 6 months after the first-line therapy, the same chemotherapy regimen can be repeated; if relapse occurs sooner than 3-6 months, the options for second-line chemotherapy include irinotecan, topotecan, paclitaxel, docetaxel, vinorelbine, gemcitabine, and temozolomide (Kunz et al. 2013).

Despite controversy (Kunz et al. 2013), antitumor effects of somatostatin analogs have been observed in advanced nonfunctioning pNET (Rinke et al. 2009, Igarashi et al. 2015). Peptide receptor-conjugated radiotherapy (with ${ }^{177} \mathrm{Lu}$ - or ${ }^{90}$ Y-labeled somatostatin analogs) is currently under investigation.

\section{Prognosis}

The American Joint Committee on Cancer (AJCC) and World Health Organization (WHO) grading systems are useful in predicting pNET disease progression, and tissue immunohistochemistry profile provides additional values (Morin et al. 2013). Other poor prognostic considerations

Published by Bioscientifica Ltd 
include a high Ki-67 index/proliferative rate, bone or liver metastasis (Lee et al. 2015), older age, longer disease history, and associated tumor in the pancreatic head (Keutgen et al. 2016).

It is estimated that at least $50 \%$ of pNET eventually recur or metastasize. Their malignant potential correlates with tumor size and extent of lymph node metastasis. Some $50-70 \%$ of pNET in the size range $2-3 \mathrm{~cm}$ are associated with lymph node metastases, and $25-40 \%$ of pNET larger than $4 \mathrm{~cm}$ are associated with hepatic metastases (Yates et al. 2015). Patients with nonfunctioning pNET $>3 \mathrm{~cm}$ have significantly lower survival compared with patients with tumors less than $1 \mathrm{~cm}$ or between 1 and $3 \mathrm{~cm}$ (Triponez et al. 2006).

\section{Insulinoma in MEN1}

In MEN1 patients, insulinoma is the second most common functioning pancreatico-duodenal neuroendocrine tumor after gastrinoma, with a prevalence of $10-18 \%$ in MEN1 (Goudet et al. 2010, Bartsch et al. 2013). Insulinoma in MEN1 patients has a significantly higher recurrence rate (21\%) than sporadic insulinoma (7\%) after a 20-year follow-up (Service et al. 1991).

\section{Clinical features}

Neuroglycopenic and adrenergic symptoms such as confusion, visual disturbances, and diaphoresis are typical presenting symptoms of insulinoma. Insulinoma can be the first presentation of MEN1, with a median age of 30 at diagnosis (Bartsch et al. 2013). In a Japanese MEN1 cohort, insulinoma was diagnosed at median age of 35, with $24 \%$ recognized before age of 20 (Sakurai et al. 2012). Insulinomas are usually benign and only $10 \%$ cases are malignant.

\section{Diagnosis}

Diagnosis of insulinoma in patients with typical neuroglycopenic and/or adrenergic symptoms of hypoglycemia requires demonstration of Whipple's triad, and can be accomplished through supervised fasting (Hirshberg et al. 2000). Diagnosis of insulinoma in a young patient should prompt genetic testing for MEN1 gene mutation: among MEN1 patients diagnosed before age 21, some $12 \%$ presented with insulinoma (Goudet et al. 2015). MEN1 accounts for about 10\% of all insulinoma cases.

Localization of insulinoma in anticipation of surgery should proceed only after biochemical workup has established the diagnosis of insulinoma.
Noninvasive localization studies may not prove adequate, since CT and MRI correctly identified insulinoma in fewer than half of cases, and only one-third of cases were detected by transabdominal ultrasonography (Taye \& Libutti 2015). The successful localization of an insulinoma with ${ }^{68} \mathrm{Ga}$-DOTATATE PET/CT was described in a recent case report (Sadowski et al. 2014). Calcium-stimulated angiography provided correct preoperative localization in nearly $90 \%$ of insulinomas $(n=76)$ in one tertiary referral center (Guettier et al. 2009). Endoscopic ultrasound also demonstrates high sensitivity for insulinoma localization, especially for pancreatic head lesions (Anderson et al. 2000). During surgery, the combination of palpation and intraoperative ultrasonography can detect $>90 \%$ of insulinomas (Nikfarjam et al. 2008).

\section{Management}

Surgery is the principal treatment modality for insulinoma in MEN1 patients. In MEN1 patients, approximately 50\% of insulinomas are located in the tail of the pancreas, with the remainder split roughly evenly between the body and the head (Vezzosi et al. 2015). The choice of operation depends on the presence and location of a dominant lesion. Enucleation or segmental resection can be used for MEN1 patients with a single or dominant lesion (Bartsch et al. 2013). This approach is associated with the fewest postoperative complications but risks a higher recurrence rate. Distal pancreatectomy has the lowest rate of recurrence (Vezzosi et al. 2015). Intraoperative ultrasonography and monitoring serum level glucose/ insulin are useful in the evaluation of completeness of insulinoma resection (Machado 2012). Diabetes, pancreatic fistula, pancreatitis, and sepsis are common complications after surgery (Vezzosi et al. 2015).

Medical therapy may be used for patients who are not surgical candidates, or as a bridging strategy before surgery. Insulinoma patients can be treated with frequent carbohydrate diet, diazoxide, or even corticosteroids (Kunz et al. 2013). Somatostatin analogs, including lanreotide and octreotide, have been used to alleviate symptoms caused by excessive hormone secretion. This approach can be considered in patients with clinically advanced disease and positive somatostatin receptor scintigraphy (Jawiarczyk et al. 2012).

\section{Gastrinoma in MEN1}

Approximately, 30\% of MEN1 patients have gastrinoma, which nearly always manifests as Zollinger-Ellison

Published by Bioscientifica Ltd 
syndrome (ZES), the constellation of gastric acid hypersecretion with severe acid-related peptic disease, and/or diarrhea (Goudet et al. 2004). Gastrinomas in MEN1 most commonly arise in the duodenum (>70\%), especially in the first part of the duodenum including the bulb, but can also originate in the pancreas or biliary tree (Tonelli et al. 2013). MEN1 accounts for about 25\% of all ZES.

\section{Clinical features}

Clinical findings include epigastric or right upper quadrant pain, diarrhea, esophageal reflux, heartburn, or weight loss, which are all related to excessive production of gastric acid. Vomiting may indicate partial or complete gastric outlet obstruction, and hematemesis and/or melena indicate gastrointestinal bleeding. Ulcer perforation may cause acute abdomen with significant complications or even death if not promptly recognized and treated. The clinical symptoms of gastrinoma usually manifest before age 40-50 in MEN1 patients (Gibril et al. 2004).

\section{Diagnosis}

Characteristic clinical symptoms, such as severe heartburn or diarrhea, associated with elevated fasting gastrin levels are suggestive but not diagnostic of ZES. The formal diagnosis of ZES usually requires the demonstration of hypergastrinemia with the exclusion of achlorhydria by the demonstration of an acidic gastric $\mathrm{pH}$. Somatostatin receptor scintigraphy is the single most sensitive method for imaging primary or metastatic liver lesions in patients with gastrinoma, and is as sensitive as CT, MRI, ultrasound, and selective angiography combined (Gibril et al. 1996). Biopsy through upper GI endoscopy frequently establishes the diagnosis. The majority of gastrinomas in MEN1 arise in the duodenum, whereas sporadic gastrinomas are more commonly located in the pancreas (Jensen et al. 2006). Although local lymph node involvement can frequently be documented upon initial surgery for gastrinoma in MEN1, the malignant potential of sporadic gastrinomas is greater than those in the context of MEN1 (MacFarlane et al. 1995, Jensen et al. 2006).

\section{Management}

There are proponents of either surgical or nonsurgical treatment options for MEN1-associated gastrinoma.
Many experts recommend the use of an escalating medical regimen with proton pump inhibitors such as omeprazole and pantoprazole to control symptoms and acid (Ito et al. 2013b), pointing to the difficulty of establishing a biochemical cure via surgery in MEN1 patients (MacFarlane et al. 1995). Other centers advocate for surgical intervention for duodenal and pancreatic gastrinoma in MEN1, citing significant biochemical cure rates with aggressive surgery (Imamura et al. 2011, Lopez et al. 2013). Since correction of primary hyperparathyroidism significantly decreases gastrin level and improves basal acid output (Norton et al. 2008), surgical treatment for primary hyperparathyroidism is generally recommended before any surgery for gastrinoma (Machado 2012, Krampitz \& Norton 2013).

\section{Bronchial and thymic neuroendocrine tumors in MEN1}

Thymic NETs (sometimes referred to as 'carcinoid tumors') occur in $2-8 \%$ of individuals with MEN1. These tumors have a male predominance and a high mortality rate, with a 10-year survival rate between 25 and $36.1 \%$. On the contrary, bronchial NET are more common (13\%) in MEN1, with less gender bias and a more favorable 10-year survival rate (71.1\%) (Giusti et al. 1993, Jensen et al. 2008, de Laat et al. 2014, Singh Ospina et al. 2015). Risk factor and mortality analysis of a large cohort of European patients with MEN1 confirmed that thymic NET carries a significantly higher mortality with a hazard ratio of 4.29 , while bronchial NET usually follows an indolent course and is not associated with an increased risk of death (Goudet et al. 2010).

\section{Clinical features}

Patients with thymic or bronchial NET can be asymptomatic or have chest discomfort or cough. Although most thymic and bronchial NET in MEN1 are hormonally nonfunctioning (Singh Ospina et al. 2015), functioning NET can rarely produce symptoms related to the excessive hormone release. Carcinoid syndrome resulting from primary thymic or bronchial NET is rare. Adrenocorticotropic hormone (ACTH) secreting and growth hormone-releasing hormone (GHRH) secreting thymic tumors have been reported in MEN1 patients resulting in ectopic Cushing's syndrome and acromegaly, respectively (Boix et al. 2002, Takagi et al. 2006, Li et al. 2014). In patients with advanced disease, symptoms and signs can develop from local invasion,

Published by Bioscientifica Ltd 
mediastinal lymphadenopathy, and pulmonary and bone metastases (Otake et al. 2010, Thomas de Montpreville et al. 2013). No genotype-phenotype correlation has been observed between MEN1 mutation and the presence of thymic or bronchial NET (Goudet et al. 2009).

\section{Diagnosis}

No circulating tumor marker is sensitive enough to be used for the diagnosis of thymic or bronchial NET (Goudet et al. 2009). For tumors that are greater than $1 \mathrm{~cm}$ size, CT and MRI have sensitivity close to $100 \%$ to identify the thymic or bronchial NET. The typical finding on CT scan is an irregular mass enhanced with intravenous contrast that may also contain calcification (Figs 2 and 3). Conventional somatostatin receptor scintigraphy has a lower sensitivity (around 75\%) to detect thymic NET (Gibril et al. 2003). Imaging by ${ }^{18} \mathrm{~F}$-fluorodeoxyglucose (FDG) PET/CT may be useful to detect locally invasive lesions and distant metastases (Abe et al. 2008, Recuero Diaz et al. 2013). CT-guided needle biopsy of thymic NET or bronchoscopic biopsy of bronchial NET, followed by pathological examination of the specimens, help confirm diagnosis after clinical evaluation and radiological workup.

\section{Management}

Because of the malignant potential of thymic NET, prophylactic transcervical thymectomy at the time of initial parathyroidectomy is frequently recommended (Gibril et al. 2003, Goudet et al. 2009, Altemir Trallero et al . 2012, Recuero Diaz et al. 2013). However, such surgical prophylaxis may not always prevent the occurrence of thymic NET in MEN1 patients (Burgess et al. 2001, Goudet et al. 2009). Prophylactic thymectomy may have the additional benefit of preventing recurrent or persistent hyperparathyroidism, since in one study of 66 MEN1 patients undergoing initial parathyroid surgery, nearly $30 \%$ of patients demonstrated intrathymic parathyroid tissue following such prophylactic thymectomy (Powell et al. 2008). Screening for thymic or bronchial NET by chest CT or MRI should be implemented at baseline and every 1-2 years thereafter (Miller et al. 2008, Thakker et al. 2012). It must be recognized, however, that lifelong surveillance for a low-prevalence condition also carries potential risks, including overdetection and overtreatment, increased anxiety, exposure to radiation, and medical cost.

For thymic NET in MEN1 patients, en bloc resection of thymus and adjacent compromised structures is

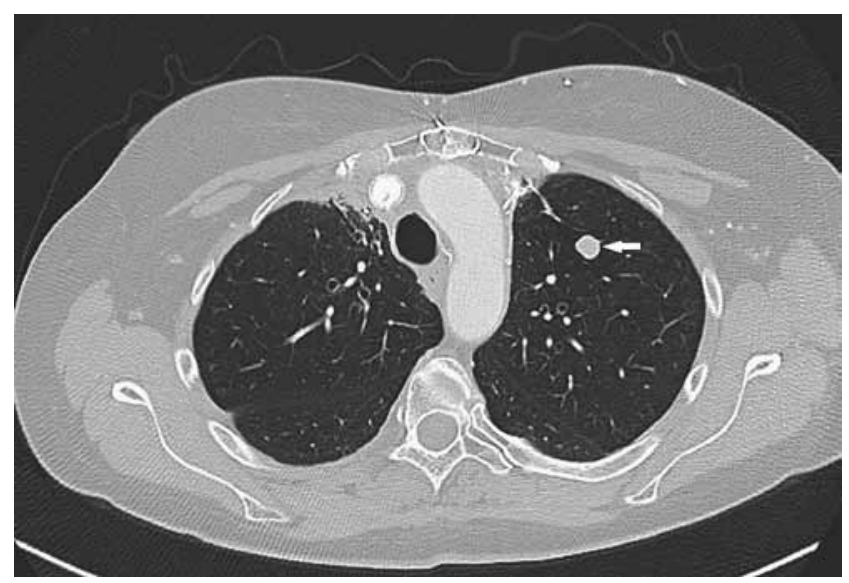

Figure 2

CT of the chest showed a lung nodule of $1.1 \mathrm{~cm}$ diameter located in the left upper lobe (marked by arrow) in an MEN1 patient. It was surgically resected and proven to be a well-differentiated pulmonary neuroendocrine tumor ('bronchial carcinoid').

recommended (Recuero Diaz et al. 2013). Observation of bronchial NET with surgical resection of any hormonally functional tumors, tumors causing compressive symptoms, or tumors demonstrating significant interval growth is the main management options.

There is only limited data on medical therapy for nonresectable thymic or bronchial NET in MEN1 patients. There is one case report that a partial response was achieved in a MEN1 patient with thymic NET after cisplatin and etoposide chemotherapy (Amano et al. 2010). Radiation therapy can be utilized for bone metastases.

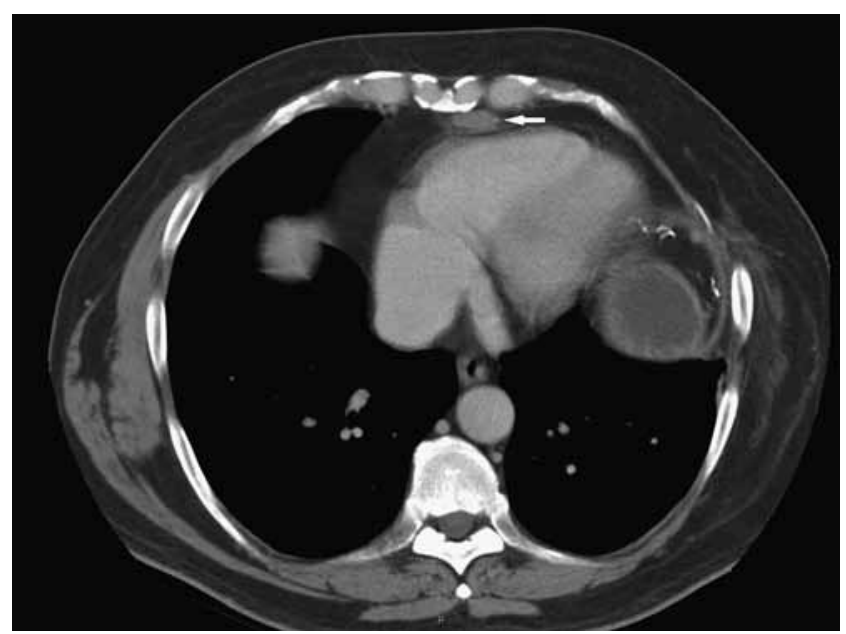

Figure 3

CT of the chest of an MEN1 patient with a history of thymic neuroendocrine tumor and prior surgical resection, showed a $2.5 \times 1.2 \mathrm{~cm}$ suspicious mediastinal lesion (marked by arrow). It was resected and proven to be a thymic neuroendocrine tumor by surgical pathology.

Published by Bioscientifica Ltd 


\section{MEN2A-associated medullary thyroid cancer}

Classical MEN2A is a heritable syndrome characterized by medullary thyroid cancer (MTC), pheochromocytoma, and primary hyperparathyroidism (virtually always due to benign disease). MEN2A results from germline mutations in the RET protooncogene and is transmitted in an autosomal dominant manner. Three other nonclassical variants of MEN2A are now recognized: MEN2A with cutaneous lichen amyloidosis, MEN2A with Hirschsprung's disease, and familial MTC (individuals with RET germline mutations from families who have MTC but not pheochromocytoma or primary hyperparathyroidism). MTC arises from parafollicular cells of the thyroid (C-cells) and often develops in early life in MEN2A with an overall penetrance approaching 100\% (Wells et al. 2015). There is a genotype-phenotype association between different RET mutations and clinical manifestation/prognosis of MTC. Current guidelines recommend prophylactic thyroidectomy depending on the risk associated with the particular RET gene mutation (Wells et al. 2015).

\section{Clinical features}

Unlike sporadic MTC that most commonly presents in the fourth to sixth decade of life, the incidence of MEN2-associated MTC peaks in the second decade of life. Index cases usually present with a solitary thyroid nodule with or without cervical lymphadenopathy. In rare cases, MTC can cause Cushing's syndrome through ectopic production of ACTH or CRH.

\section{Molecular pathophysiology}

MEN2A is caused by gain-of-function mutation in the RET protooncogene. RET encodes a transmembrane receptor tyrosine kinase which, in conjunction with glial-derived neurotrophic factor (GDNF)family $\alpha$ coreceptors, binds GDNF family ligands (Wells \& Santoro 2009). In 95\% of patients, classical MEN2A is associated with germline missense mutations in RET codons $609,611,618$, or 620 of exon 10 or codon 634 of exon 11, which map to the receptor's extracellular cysteine-rich domain (Frank-Raue \& Raue 2015). MEN2A with cutaneous lichen amyloidosis is nearly always associated with mutation of codon 634, while patients with MEN2A and Hirschsprung's disease typically harbor mutations involving RET exon 10 (Frank-Raue \& Raue 2015).

\section{Diagnosis}

Neoplastic C-cells of thyroid gland have the potential to secrete several hormones or biogenic amines, including ACTH, $\beta$-melanocyte stimulating hormone, calcitonin, carcinoembryonic antigen (CEA), and chromogranin A. Circulating calcitonin and CEA levels are related to C-cell mass and are valuable tumor markers in patients with MTC (Wells et al. 2015). Serum calcitonin level has a high sensitivity but a low specificity for the diagnosis of MTC. It can be elevated in many other medical conditions, including hypercalcemia and hypergastrinemia, and can also be abnormal after the use of certain medications, such as proton pump inhibitors, beta-blockers, and glucocorticoids (Toledo et al. 2009). Higher basal levels and stimulated calcitonin levels increase its predicative value for MTC (Karges 2010).

A higher level of calcitonin may also be indicative of lymph node metastases and can be used to stratify disease and guide neck dissection. In one study, when lymph node metastases were present in the ipsilateral central and lateral neck, contralateral central neck, contralateral lateral neck, and upper mediastinum, basal calcitonin levels were found to be greater than 20,50, 200, and $500 \mathrm{pg} / \mathrm{mL}$, respectively (Machens \& Dralle 2010). In patients with calcitonin levels greater than $200 \mathrm{pg} / \mathrm{mL}$, bilateral compartment neck surgery should be considered (Machens \& Dralle 2010).

Determination of procalcitonin, the precursor peptide of calcitonin, is comparable to calcitonin in diagnosing primary tumor/extrathyroidal extension and confirming biochemical cure. Because it is more stable and has a longer half-life, procalcitonin has been recommended for use in the community setting (Machens et al. 2014).

CEA is not a specific marker for MTC, and is not useful for diagnosis. Nevertheless, concurrent measurement of CEA and calcitonin has some benefit in recognizing poorly differentiated or invasive MTC (Wells et al. 2015). It can be elevated in the presence of positive heterophilic antibody, tobacco smoking, gastrointestinal tract inflammatory disease, benign lung disease, or in nonthyroid malignancies (Wells et al. 2015).

Commonly used imaging tests to detect and follow primary and secondary MTCs include neck US, chest CT, liver MRI, bone scintigraphy, and axial skeleton MRI. FDG-PET scan is less sensitive and has low prognostic value (Giraudet et al. 2007).

Genetic testing is a critical step in diagnosing MEN2A, and also has the advantage of identifying patients at risk for MTC to allow for prophylactic thyroidectomy. If a

Published by Bioscientifica Ltd. 
family member of an index case with a known MEN2Aassociated RET mutation is asymptomatic and has negative genetic test, biochemical and image testing can be avoided. American Thyroid Association guidelines recommend starting genetic testing by analyzing RET mutations in the exons $8,10,11,13,14,15$, and 16 . If there is a high clinical suspicion for MEN2A in a patient or family without a known RET mutation, a negative initial genetic testing result warrants sequencing of entire coding region of the RET gene because it is exceedingly rare that a patient diagnosed with MEN2A has no RET germline mutation (Wells et al. 2015).

\section{Management}

The timing of prophylactic thyroidectomy is based on the specific RET mutation, and in some cases, serum calcitonin level. Bilateral central neck dissection can be considered for patients with elevated calcitonin level. Patients assigned American Thyroid Association risk stratification levels A to C, with normal basal, and simulated calcitonin levels, may be operated without central neck dissection (Niederle et al. 2014).

Surgical cure of MTC might be achieved in patients with negative nodal spread or only a few lymph node metastases (Machens \& Dralle 2015). There are different opinions regarding neck lymph node dissection. Some authors propose that central lymph node dissection should be considered for all MTC patients, but lateral lymph node dissection be determined by tumor size, location, and extent of lymph node disease (Kunz et al. 2013). Other authors recommend the use of radiological/clinical evaluation or calcitonin level to guide lymph node compartment dissection (Wells et al. 2015).

In advanced MTC that has invaded surrounding structures, extensive debulking surgery involving possible laryngectomy, esophagectomy, or laryngopharyngectomy may be indicated based on patient's life expectancy and other medical comorbidities, in order to maintain maximal functionality of speech and deglutition. Cytoreductive surgery, external beam radiotherapy, embolization, systemic medical therapy, and other nonsurgical therapies can be considered in order to maintain local tumor control or improve life quality (Wells et al. 2015).

In advanced MTC, somatostatin analogs can be used for refractory diarrhea, which is the major clinical symptom of metastatic disease. Many EGFR-targeting agents also inhibit the RET tyrosine kinase, and can be considered for systemic therapy (Wells et al. 2015). Two tyrosine kinase inhibitors, vandetanib (Caprelsa) and cabozantinib (Cometriq), are approved by the FDA to be used as first-line therapy in progressive metastatic MTC with significant tumor burden. In randomized, double-blind, Phase III trials, both vandetanib and cabozantinib showed statistically significant improvement in progressionfree survival compared with placebo (Wells et al. 2012, Elisei et al. 2013).

\section{MEN2A-associated pheochromocytoma}

Pheochromocytomas are neuroendocrine tumors that originate from the catecholamine-synthesizing chromaffin cells of the adrenal medulla or from extraadrenal chromaffin tissue. MEN2A patients have a 50\% lifetime risk to develop pheochromocytoma, which nearly always arise in the adrenal glands (King \& Pacak 2014). MEN2A patients have 50-67\% chance of developing bilateral disease (Castinetti et al. 2014, 2016, Wells et al. 2015, Rajan et al. 2016), compared with 10\% in general pheochromocytoma population. Pheochromocytoma in MEN2A is rarely malignant, and is not associated with a shortened survival (Thosani et al. 2013).

\section{Clinical features}

Pheochromocytoma can be the presenting manifestation of MEN2A (Kinlaw et al. 2005). Pheochromocytomas in MEN2A typically hypersecrete epinephrine and can result in elevated blood pressure, rapid or forceful heartbeat, profound sweating, or even hypertensive crisis and cardiac arrest (Zwolak et al. 2015). MEN2A patients with unilateral pheochromocytoma can develop a contralateral lesion within the next 10 years (Wells et al. 2015, Rajan et al. 2016), underscoring the need for proper follow-up surveillance screening.

\section{Diagnosis}

Several studies have shown that the penetrance of pheochromocytoma is correlated with the ATA (American Thyroid Association) risk classification of RET gene mutations (Machens et al. 2005, 2013, Quayle et al. 2007, Rowland et al. 2013). Based on these findings, the ATA issued guidelines in 2015 that recommend MEN2A patients carrying high-risk RET germline mutations (such as A883F, C634F/G/R/S/W/Y; as well as M918T in MEN2B) should start screening for pheochromocytoma at age 11, while MEN2A patients with other moderate-risk RET germline mutations should start screening at age of 16 (Wells et al. 2015). Screening for pheochromocytoma in the context

Published by Bioscientifica Ltd 
of MEN2A consists of measuring free plasma epinephrine or metanephrine and/or $24 \mathrm{~h}$ urinary metanephrines. Once biochemical evidence of pheochromocytoma is established, the recommended imaging modalities include CT, MRI, ${ }^{123}$ I-metaiodobenzylguanindine (MIBG) scintigraphy, ${ }^{18} \mathrm{~F}$-fluorodopamine $\left({ }^{18} \mathrm{~F}-\mathrm{FDA}\right)-\mathrm{PET}$, and ${ }^{18} \mathrm{~F}-d i h y d r o x y p h e n y l a l a n i n e ~(18 \mathrm{~F}-\mathrm{DOPA})-\mathrm{PET}$ (Taieb et al. 2014).

Although fewer than 5\% of pheochromocytomas in MEN2A are malignant (Ilias \& Pacak 2009), the diagnosis can be made based on the documentation of extraadrenal involvement, nodal or distant metastases, or histopathologic features including high Ki-67/mitotic rate and/or abnormal nuclear pleiomorphism.

\section{Management}

Biochemically established pheochromocytoma should be surgically removed before the surgery for MTC or HPTH, and blood pressure should be controlled with alpha-blockade before surgery.

Laparoscopic resection is appropriate for localized disease. In a retrospective study that compared 438 adrenalectomy and 114 adrenal-sparing surgeries in MEN2 patients with pheochromocytoma, no difference was seen in recurrence rate or disease-free survival. About half of bilateral pheochromocytoma patients (57\%) had adrenal sparing surgery and did not become steroid-dependent (Castinetti et al. 2014). Due to the high prevalence of bilateral disease and the relatively low malignant potential of pheochromocytoma in MEN2A, cortical sparing surgery or subtotal adrenalectomy should be considered as an alternative procedure to preserve adrenal cortical function (Asari et al. 2006, Taieb et al. 2014, Wells et al. 2015).

Open resection is reserved for malignant or invasive pheochromocytoma, with cytoreductive resection for unresectable disease (Kunz et al. 2013). Progressive disease can be treated with external beam radiation, ${ }^{131}$ I-MIBG treatment in ${ }^{123}$ I-MIBG imaging-positive cases, or systemic chemotherapy with cyclophosphamide, vincristine, and dacarbazine (CVD).

\section{Conclusions and future directions}

Endocrine and nonendocrine tumors are common in familial syndromes of hyperparathyroidism due to germline mutation of tumor suppressors or protooncogenes. These tumors often have different malignant potentials and distinct disease courses, compared with their sporadic counterparts in general population. Our recognition of germline RET activation as the originating molecular defect in MEN2A has accelerated the identification of several tyrosine kinase inhibitors as rational and promising therapeutic agents for MEN2A-associated malignancies. On the other hand, mutations in MEN1 and CDC73 genes are loss-offunction mutations, similar to the findings in other tumor-suppressor genes, such as APC. It has proven to be very difficult to restore or compensate for the lost function of these mutated tumor-suppressor genes through a pharmacologic approach. The experience from other hereditary tumors may be helpful to guide the development of new therapies in the future. For instance, in the field of ovarian cancer, there has been success in using poly (ADP-ribose) polymerase (PARP) inhibitors to treat patients with germline $B R C A$ mutation by causing synthetic lethality (Farmer et al. 2005, Ledermann 2016). Although disease-specific surveillance and treatment strategies are preferred, there is a paucity of randomized clinical trial data to guide management because of the rarity of these familial syndromes. Advances in tumor imaging modalities, such as ${ }^{68} \mathrm{Ga}$-based somatostatin receptor scintigraphy, and the greater understanding that is emerging from patient registries that support large-scale cooperative clinical studies in Europe and North America on the natural history and therapeutic outcomes of these rare diseases are quite encouraging. To continue these promising developments, it is important that patients with familial syndromes of hyperparathyroidism and rare endocrine malignancies be referred to specialized research-oriented centers that participate in cooperative clinical studies. This approach will allow critical research to be performed at a limited number of cooperating institutes and ensure an adequate volume of patients. Such a strategy, in conjunction with advances in basic and translational science, should allow the thorough and conclusive exploration of novel and promising initiatives to improve the diagnosis, imaging, surveillance, and surgical and medical therapies of these highly morbid endocrine malignancies.

Declaration of interest

The authors declare that there is no conflict of interest that could be perceived as prejudicing the impartiality of this review.

\section{Funding}

This work was supported by the Intramural Research Program of the $\mathrm{NIH}$, The National Institute of Diabetes and Digestive and Kidney Diseases (NIDDK).

Published by Bioscientifica Ltd 


\section{Acknowledgements}

The authors thank Drs Stephen Marx, Lee Weinstein, Monica Skarulis, and Michael Collins for many helpful discussions, as well as their encouragement and support. They also thank Mr Craig Cochran and the patients, fellows, and nursing staff of 5NW and OP9 in the NIH Clinical Center. The Intramural Research Program of the National Institute of Diabetes and Digestive and Kidney Diseases supported this research.

\section{References}

Abe T, Sato M, Okumura T, Shioyama Y, Kiyoshima M, Asato Y, Saito H, Iijima T, Amemiya R \& Nagai H 2008 FDG PET/CT findings of thymic carcinoid and bronchial carcinoid in a patient with multiple neuroendocrine neoplasia type1. Clinical Nuclear Medicine 33 778-779. (doi:10.1097/RLU.0b013e318187efef)

Altemir Trallero J, Armengod Grao L, Aguillo Gutierrez E, Cabrejas Gomez C, Ocon Breton J \& Garcia Garcia B 2012 Thymic carcinoid in the setting of a multiple endocrine neoplasia syndrome (MEN 1). Prophylactic thymectomy? Endocrinología y Nutrición 59 142-144.

Amano H, Yamada T, Jujoh T, Kuroda F, Sakao S, Tada Y, Kurosu K, Kasahara Y, Tanabe N, Takiguchi Y, et al. 2010 [Case of thymic carcinoid associated with multiple endocrine neoplasia type I treated effectively with chemotherapy]. Nihon Kokyuki Gakkai Zasshi 48 855-859.

Anderson MA, Carpenter S, Thompson NW, Nostrant TT, Elta GH \& Scheiman JM 2000 Endoscopic ultrasound is highly accurate and directs management in patients with neuroendocrine tumors of the pancreas. American Journal of Gastroenterology 95 2271-2277. (doi:10.1111/j.1572-0241.2000.02480.x)

Asare EA, Sturgeon C, Winchester DJ, Liu L, Palis B, Perrier ND, Evans DB, Winchester DP \& Wang TS 2015 Parathyroid carcinoma: an update on treatment outcomes and prognostic factors from the National Cancer Data Base (NCDB). Annals of Surgical Oncology 22 3990-3995. (doi:10.1245/s10434-015-4672-3)

Asari R, Scheuba C, Kaczirek K \& Niederle B 2006 Estimated risk of pheochromocytoma recurrence after adrenal-sparing surgery in patients with multiple endocrine neoplasia type 2A. Archives of Surgery 141 1199-1205. (doi:10.1001/archsurg.141.12.1199)

Bartsch DK, Albers M, Knoop R, Kann PH, Fendrich V \& Waldmann J 2013 Enucleation and limited pancreatic resection provide long-term cure for insulinoma in multiple endocrine neoplasia type 1 . Neuroendocrinology 98 290-298. (doi:10.1159/000357779)

Betea D, Bradwell AR, Harvey TC, Mead GP, Schmidt-Gayk H, Ghaye B, Daly AF \& Beckers A 2004 Hormonal and biochemical normalization and tumor shrinkage induced by anti-parathyroid hormone immunotherapy in a patient with metastatic parathyroid carcinoma. Journal of Clinical Endocrinology \& Metabolism 89 3413-3420.

Boix E, Pico A, Pinedo R, Aranda I \& Kovacs K 2002 Ectopic growth hormone-releasing hormone secretion by thymic carcinoid tumour. Clinical Endocrinology 57 131-134. (doi:10.1046/ j.1365-2265.2002.01535.x)

Bowyer SE, White AM, Ransom DT \& Davidson JA 2013 Resistant hypercalcaemia in metastatic parathyroid carcinoma. Medical Journal of Australia 198 559-561. (doi:10.5694/mja12.11243)

Bradley KJ, Cavaco BM, Bowl MR, Harding B, Cranston T, Fratter C, Besser GM, Conceicao Pereira M, Davie MW, Dudley N, et al. 2006 Parafibromin mutations in hereditary hyperparathyroidism syndromes and parathyroid tumours. Clinical Endocrinology 64 299-306. (doi:10.1111/j.1365-2265.2006.02460.x)

Bradley KJ, Bowl MR, Williams SE, Ahmad BN, Partridge CJ, Patmanidi AL, Kennedy AM, Loh NY \& Thakker RV 2007 Parafibromin is a nuclear protein with a functional monopartite nuclear localization signal. Oncogene 26 1213-1221. (doi:10.1038/ sj.onc.1209893)
Bricaire L, Odou MF, Cardot-Bauters C, Delemer B, North MO, Salenave S, Vezzosi D, Kuhn JM, Murat A, Caron P, et al. 2013 Frequent large germline HRPT2 deletions in a French National cohort of patients with primary hyperparathyroidism. Journal of Clinical Endocrinology \& Metabolism 98 E403-E408.

Burgess JR, Giles N \& Shepherd JJ 2001 Malignant thymic carcinoid is not prevented by transcervical thymectomy in multiple endocrine neoplasia type 1. Clinical Endocrinology 55 689-693. (doi:10.1046/j.1365-2265.2001.01348.x)

Carpten JD, Robbins CM, Villablanca A, Forsberg L, Presciuttini S, Bailey-Wilson J, Simonds WF, Gillanders EM, Kennedy AM, Chen JD, et al. 2002 HRPT2, encoding parafibromin, is mutated in hyperparathyroidism-jaw tumor syndrome. Nature Genetics 32 676-680. (doi:10.1038/ng1048)

Castinetti F, Qi XP, Walz MK, Maia AL, Sanso G, Peczkowska M, Hasse-Lazar K, Links TP, Dvorakova S, Toledo RA, et al. 2014 Outcomes of adrenal-sparing surgery or total adrenalectomy in phaeochromocytoma associated with multiple endocrine neoplasia type 2: an international retrospective population-based study. Lancet Oncology 15 648-655.

Castinetti F, Taieb D, Henry JF, Walz M, Guerin C, Brue T, Conte-Devolx B, Neumann HP \& Sebag F 2016 MANAGEMENT OF ENDOCRINE DISEASE: Outcome of adrenal sparing surgery in heritable pheochromocytoma. European Journal of Endocrinology 174 R9-R18.

Chandrasekharappa SC, Guru SC, Manickam P, Olufemi SE, Collins FS, Emmert-Buck MR, Debelenko LV, Zhuang Z, Lubensky IA, Liotta LA, et al. 1997 Positional cloning of the gene for multiple endocrine neoplasia-type 1. Science 276 404-407. (doi:10.1126/ science.276.5311.404)

Chiofalo MG, Sparaneo A, Chetta M, Franco R, Baorda F, Cinque L, Granatiero M, D'Agruma L, Pezzullo L, Scillitani A, et al. 2014 A novel CDC73 gene mutation in an Italian family with hyperparathyroidism-jaw tumour (HPT-JT) syndrome. Cellular Oncology 37 281-288. (doi:10.1007/s13402-014-0187-3)

de Laat JM, Pieterman CR, Weijmans M, Hermus AR, Dekkers OM, de Herder WW, van der Horst-Schrivers AN, Drent ML, Bisschop PH, Havekes B, et al. 2013 Low accuracy of tumor markers for diagnosing pancreatic neuroendocrine tumors in multiple endocrine neoplasia type 1 patients. Journal of Clinical Endocrinology \& Metabolism 98 $4143-4151$.

de Laat JM, Pieterman CR, van den Broek MF, Twisk JW, Hermus AR, Dekkers OM, de Herder WW, van der Horst-Schrivers AN, Drent ML, Bisschop PH, et al. 2014 Natural course and survival of neuroendocrine tumors of thymus and lung in MEN1 patients. Journal of Clinical Endocrinology \& Metabolism 99 3325-3333.

Dehghani H, Reith C \& Hahnel AC 2005 Subcellular localization of protein kinase $\mathrm{C}$ delta and epsilon affects transcriptional and post-transcriptional processes in four-cell mouse embryos. Reproduction 130 453-465. (doi:10.1530/rep.1.00572)

Do Cao C, Aubert S, Trinel C, Odou MF, Bayaram M \& Patey M 2015 Parathyroid carcinoma: diagnostic criteria, classification, evaluation. Annales d'Endocrinologie 76 165-168. (doi:10.1016/j. ando.2015.03.016)

Elisei R, Schlumberger MJ, Muller SP, Schoffski P, Brose MS, Shah MH, Licitra L, Jarzab B, Medvedev V, Kreissl MC, et al. 2013 Cabozantinib in progressive medullary thyroid cancer. Journal of Clinical Oncology 31 3639-3646. (doi:10.1200/JCO.2012.48.4659)

Farmer H, McCabe N, Lord CJ, Tutt AN, Johnson DA, Richardson TB, Santarosa M, Dillon KJ, Hickson I, Knights C, et al. 2005 Targeting the DNA repair defect in BRCA mutant cells as a therapeutic strategy. Nature 434 917-921. (doi:10.1038/nature03445)

Frank-Raue K \& Raue F 2015 Hereditary medullary thyroid cancer genotype-phenotype correlation. Recent Results in Cancer Research 204 139-156. (doi:10.1007/978-3-319-22542-5) 
Gao WC, Ruan CP, Zhang JC, Liu HM, Xu XY, Sun YP \& Wang Q 2010 Nonfunctional parathyroid carcinoma. Journal of Cancer Research and Clinical Oncology 136 969-974. (doi:10.1007/ s00432-009-0740-z)

Gibril F, Reynolds JC, Doppman JL, Chen CC, Venzon DJ, Termanini B, Weber HC, Stewart CA \& Jensen RT 1996 Somatostatin receptor scintigraphy: its sensitivity compared with that of other imaging methods in detecting primary and metastatic gastrinomas. A prospective study. Annals of Internal Medicine 125 26-34. (doi:10.7326/0003-4819-125-1-199607010-00005)

Gibril F, Chen YJ, Schrump DS, Vortmeyer A, Zhuang Z, Lubensky IA, Reynolds JC, Louie A, Entsuah LK, Huang K, et al. 2003 Prospective study of thymic carcinoids in patients with multiple endocrine neoplasia type 1. Journal of Clinical Endocrinology \& Metabolism $\mathbf{8 8}$ 1066-1081.

Gibril F, Schumann M, Pace A \& Jensen RT 2004 Multiple endocrine neoplasia type 1 and Zollinger-Ellison syndrome: a prospective study of 107 cases and comparison with 1009 cases from the literature. Medicine 83 43-83. (doi:10.1097/01.md.0000112297.72510.32)

Giraudet AL, Vanel D, Leboulleux S, Auperin A, Dromain C, Chami L, Ny Tovo N, Lumbroso J, Lassau N, Bonniaud G, et al. 2007 Imaging medullary thyroid carcinoma with persistent elevated calcitonin levels. Journal of Clinical Endocrinology \& Metabolism 92 4185-4190.

Giusti F, Marini F \& Brandi ML 1993 Multiple endocrine neoplasia type 1. In GeneReviews(R). Eds RA Pagon, MP Adam, HH Ardinger, SE Wallace, A Amemiya, LJH Bean, TD Bird, CT Fong, HC Mefford, RJH Smith, et al. Seattle, WA, USA: University of Washington, Seattle.

Goudet P, Peschaud F, Mignon M, Nicoli-Sire P, Cadiot G, Ruszniewski P Calender A, Murat A, Sarfati E, Peix JL, et al. 2004 [Gastrinomas in multiple endocrine neoplasia type-1. A 127-case cohort study from the endocrine tumor group (ETG)]. Annales de Chirurgie 129 149-155. (doi:10.1016/j.anchir.2003.11.013)

Goudet P, Murat A, Cardot-Bauters C, Emy P, Baudin E, du Boullay Choplin H, Chapuis Y, Kraimps JL, Sadoul JL, Tabarin A, et al. 2009 Thymic neuroendocrine tumors in multiple endocrine neoplasia type 1: a comparative study on 21 cases among a series of 761 MEN1 from the GTE (Groupe des Tumeurs Endocrines). World Journal of Surgery 33 1197-1207.

Goudet P, Murat A, Binquet C, Cardot-Bauters C, Costa A, Ruszniewski P, Niccoli P, Menegaux F, Chabrier G, Borson-Chazot F, et al. 2010 Risk factors and causes of death in MEN1 disease. A GTE (Groupe d'Etude des Tumeurs Endocrines) cohort study among 758 patients. World Journal of Surgery 34 249-255. (doi:10.1007/s00268-009-0290-1)

Goudet P, Dalac A, Le Bras M, Cardot-Bauters C, Niccoli P, LevyBohbot N, du Boullay H, Bertagna X, Ruszniewski P, Borson-Chazot F, et al. 2015 MEN1 disease occurring before 21 years old: a 160-patient cohort study from the Groupe d'etude des Tumeurs Endocrines. Journal of Clinical Endocrinology \& Metabolism 100 1568-1577.

Guarnieri V, Scillitani A, Muscarella LA, Battista C, Bonfitto N, Bisceglia M, Minisola S, Mascia ML, D'Agruma L \& Cole DE 2006 Diagnosis of parathyroid tumors in familial isolated hyperparathyroidism with HRPT2 mutation: implications for cancer surveillance. Journal of Clinical Endocrinology \& Metabolism 91 2827-2832.

Guettier JM, Kam A, Chang R, Skarulis MC, Cochran C, Alexander HR, Libutti SK, Pingpank JF \& Gorden P 2009 Localization of insulinomas to regions of the pancreas by intraarterial calcium stimulation: the NIH experience. Journal of Clinical Endocrinology \& Metabolism 94 1074-1080.

Haciyanli M, Oruk G, Ucarsoy AA, Gur O \& Genc H 2011 Multiglandular parathyroid carcinoma: case report and review of the literature. Endocrine Practice 17 e79-e83.

Hahn MA \& Marsh DJ 2005 Identification of a functional bipartite nuclear localization signal in the tumor suppressor parafibromin. Oncogene 24 6241-6248. (doi:10.1038/sj.onc.1208778)
Hahn MA \& Marsh DJ 2007 Nucleolar localization of parafibromin is mediated by three nucleolar localization signals. FEBS Letters $\mathbf{5 8 1}$ 5070-5074. (doi:10.1016/j.febslet.2007.09.050)

Hara H, Igarashi A, Yano Y, Yashiro T, Ueno E, Aiyoshi Y, Ito K \& Obara T 2001 Ultrasonographic features of parathyroid carcinoma. Endocrine Journal 48 213-217. (doi:10.1507/endocrj.48.213)

Harari A, Zarnegar R, Lee J, Kazam E, Inabnet WB 3rd \& Fahey TJ 3rd 2008 Computed tomography can guide focused exploration in select patients with primary hyperparathyroidism and negative sestamibi scanning. Surgery 144 970-976. (doi:10.1016/j.surg.2008.08.029)

Harari A, Waring A, Fernandez-Ranvier G, Hwang J, Suh I, Mitmaker E, Shen W, Gosnell J, Duh QY \& Clark O 2011 Parathyroid carcinoma: a 43-year outcome and survival analysis. Journal of Clinical Endocrinology \& Metabolism 96 3679-3686.

Hirshberg B, Livi A, Bartlett DL, Libutti SK, Alexander HR, Doppman JL, Skarulis MC \& Gorden P 2000 Forty-eight-hour fast: the diagnostic test for insulinoma. Journal of Clinical Endocrinology \& Metabolism $\mathbf{8 5}$ 3222-3226.

Horie I, Ando T, Inokuchi N, Mihara Y, Miura S, Imaizumi M, Usa T, Kinoshita N, Sekine I, Kamihara S, et al. 2010 First Japanese patient treated with parathyroid hormone peptide immunization for refractory hypercalcemia caused by metastatic parathyroid carcinoma. Endocrine Journal 57 287-292. (doi:10.1507/ endocrj.K09E-283)

Howell VM, Haven CJ, Kahnoski K, Khoo SK, Petillo D, Chen J, Fleuren GJ, Robinson BG, Delbridge LW, Philips J, et al. 2003 HRPT2 mutations are associated with malignancy in sporadic parathyroid tumours. Journal of Medical Genetics $\mathbf{4 0}$ 657-663. (doi:10.1136/jmg.40.9.657)

Huang J, Gurung B, Wan B, Matkar S, Veniaminova NA, Wan K, Merchant JL, Hua X \& Lei M 2012 The same pocket in menin binds both MLL and JUND but has opposite effects on transcription. Nature 482 542-546. (doi:10.1038/nature10806)

Hundahl SA, Fleming ID, Fremgen AM \& Menck HR 1999 Two hundred eighty-six cases of parathyroid carcinoma treated in the U.S. between 1985-1995: a National Cancer Data Base Report. The American College of Surgeons Commission on Cancer and the American Cancer Society. Cancer 86 538-544. (doi:10.1002/(sici)10970142(19990801)86:3<538::aid-cncr25>3.0.co;2-k)

Igarashi $\mathrm{H}$, Hijioka M, Lee L \& Ito T 2015 Biotherapy of pancreatic neuroendocrine tumors using somatostatin analogs. Journal of Hepato-Biliary-Pancreatic Sciences 22 618-622. (doi:10.1002/jhbp.227)

Ilias I \& Pacak K 2009 Diagnosis, localization and treatment of pheochromocytoma in MEN 2 syndrome. Endocrine Regulations 43 89-93.

Imamura M 2010 Recent standardization of treatment strategy for pancreatic neuroendocrine tumors. World Journal of Gastroenterology 16 4519-4525. (doi:10.3748/wig.v16.i36.4519)

Imamura M, Komoto I, Ota S, Hiratsuka T, Kosugi S, Doi R, Awane M \& Inoue N 2011 Biochemically curative surgery for gastrinoma in multiple endocrine neoplasia type 1 patients. World Journal of Gastroenterology 17 1343-1353. (doi:10.3748/wjg.v17.i10.1343)

Ito T, Igarashi H, Uehara H, Berna MJ \& Jensen RT 2013a Causes of death and prognostic factors in multiple endocrine neoplasia type 1: a prospective study: comparison of 106 MEN1/Zollinger-Ellison syndrome patients with 1613 literature MEN1 patients with or without pancreatic endocrine tumors. Medicine 92 135-181.

Ito T, Igarashi H, Uehara H \& Jensen RT 2013b Pharmacotherapy of Zollinger-Ellison syndrome. Expert Opinion on Pharmacotherapy $\mathbf{1 4}$ 307-321.

Jackson MA, Rich TA, Hu MI, Perrier ND \& Waguespack SG 2015 CDC73-related disorders. In GeneReviews (Internet). Seattle, WA, USA: University of Washington, Seattle, 1993-2015.

Jaehning JA 2010 The Paf1 complex: platform or player in RNA polymerase II transcription? Biochimica et Biophysica Acta 1799 379-388. (doi:10.1016/j.bbagrm.2010.01.001) 
Jaenicke LA, von Eyss B, Carstensen A, Wolf E, Xu W, Greifenberg AK, Geyer M, Eilers M \& Popov N 2016 Ubiquitin-dependent turnover of MYC antagonizes MYC/PAF1C complex accumulation to drive transcriptional elongation. Molecular Cell 61 54-67. (doi:10.1016/ j.molcel.2015.11.007)

Jawiarczyk A, Bolanowski M, Syrycka J, Bednarek-Tupikowska G, Kaluzny M, Kolodziejczyk A \& Domoslawski P 2012 Effective therapy of insulinoma by using long-acting somatostatin analogue. A case report and literature review. Experimental and Clinical Endocrinology \& Diabetes 120 68-72.

Jensen RT, Niederle B, Mitry E, Ramage JK, Steinmuller T, Lewington V, Scarpa A, Sundin A, Perren A, Gross D, et al. 2006 Gastrinoma (duodenal and pancreatic). Neuroendocrinology 84 173-182.

Jensen RT, Berna MJ, Bingham DB \& Norton JA 2008 Inherited pancreatic endocrine tumor syndromes: advances in molecular pathogenesis, diagnosis, management, and controversies. Cancer 113 1807-1843. (doi:10.1002/cncr.23648)

Jumpertz von Schwartzenberg R, Elbelt U, Ventz M, Mai K, Kienitz T, Maurer L, Rose T, Ruckert JC, Strasburger CJ \& Spranger J 2015 Palliative treatment of uncontrollable hypercalcemia due to parathyrotoxicosis: denosumab as rescue therapy. Endocrinology, Diabetes \& Metabolism Case Reports 2015150082.

Karges W 2010 [Calcitonin determination for early diagnosis of medullary thyroid cancer]. Chirurg 81 620, 622-626.

Karuppiah D, Thanabalasingham G, Shine B, Wang LM, Sadler GP, Karavitaki N \& Grossman AB 2014 Refractory hypercalcaemia secondary to parathyroid carcinoma: response to high-dose denosumab. European Journal of Endocrinology 171 K1-K5.

Kebebew E, Arici C, Duh QY \& Clark OH 2001 Localization and reoperation results for persistent and recurrent parathyroid carcinoma. Archives of Surgery 136 878-885. (doi:10.1001/ archsurg.136.8.878)

Keutgen XM, Nilubol N, Glanville J, Sadowski SM, Liewehr DJ, Venzon DJ, Steinberg SM \& Kebebew E 2016 Resection of primary tumor site is associated with prolonged survival in metastatic nonfunctioning pancreatic neuroendocrine tumors. Surgery 159 311-319. (doi:10.1016/j.surg.2015.05.042)

Khadilkar KS, Budyal SR, Kasliwal R, Lila AR, Bandgar T \& Shah NS 2015 HRPT2- (CDC73) related hereditary hyperparathyroidism: a case series from western India. Endocrine Practice 21 1010-1016. (doi:10.4158/EP15648.OR)

King KS \& Pacak K 2014 Familial pheochromocytomas and paragangliomas. Molecular and Cellular Endocrinology 386 92-100. (doi:10.1016/j.mce.2013.07.032)

Kinlaw WB, Scott SM, Maue RA, Memoli VA, Harris RD, Daniels GH, Porter DM, Belloni DR, Spooner ET, Ernesti MM, et al. 2005 Multiple endocrine neoplasia 2A due to a unique C609S RET mutation presents with pheochromocytoma and reduced penetrance of medullary thyroid carcinoma. Clinical Endocrinology 63 676-682. (doi:10.1111/j.1365-2265.2005.02400.x)

Kong J, Wang O, Nie M, Shi J, Hu Y, Jiang Y, Li M, Xia W, Meng X \& Xing X 2014 Familial isolated primary hyperparathyroidism/ hyperparathyroidism-jaw tumour syndrome caused by germline gross deletion or point mutations of CDC73 gene in Chinese. Clinical Endocrinology 81 222-230. (doi:10.1111/cen.12461)

Korpi-Hyovalti E, Cranston T, Ryhanen E, Arola J, Aittomaki K, Sane T, Thakker RV \& Schalin-Jantti C 2014 CDC73 intragenic deletion in familial primary hyperparathyroidism associated with parathyroid carcinoma. Journal of Clinical Endocrinology \& Metabolism 99 3044-3048.

Kouvaraki MA, Shapiro SE, Cote GJ, Lee JE, Yao JC, Waguespack SG, Gagel RF, Evans DB \& Perrier ND 2006 Management of pancreatic endocrine tumors in multiple endocrine neoplasia type 1 . World Journal of Surgery 30 643-653. (doi:10.1007/s00268-006-0360-y)

Krampitz GW \& Norton JA 2013 Current management of the ZollingerEllison syndrome. Advances in Surgery 47 59-79. (doi:10.1016/ j.yasu.2013.02.004)
Kunz PL, Reidy-Lagunes D, Anthony LB, Bertino EM, Brendtro K, Chan JA, Chen H, Jensen RT, Kim MK, Klimstra DS, et al. 2013 Consensus guidelines for the management and treatment of neuroendocrine tumors. Pancreas 42 557-577. (doi:10.1097/ MPA.0b013e31828e34a4)

Kutcher MR, Rigby MH, Bullock M, Trites J, Taylor SM \& Hart RD 2013 Hyperparathyroidism-jaw tumor syndrome. Head \& Neck 35 E175-E177.

Lastoria S, Marciello F, Faggiano A, Aloj L, Caraco C, Aurilio M, D'Ambrosio L, Di Gennaro F, Ramundo V, Camera L, et al. 2015 Role of Ga-DOTATATE PET/CT in patients with multiple endocrine neoplasia type 1 (MEN1). Endocrine 52 488-494.

Ledermann JA 2016 PARP inhibitors in ovarian cancer. Annals of Oncology 27 i40-i44. (doi:10.1093/annonc/mdw094)

Lee L, Igarashi H, Fujimori N, Hijioka M, Kawabe K, Oda Y, Jensen RT \& Ito T 2015 Long-term outcomes and prognostic factors in 78 Japanese patients with advanced pancreatic neuroendocrine neoplasms: a single-center retrospective study. Japanese Journal of Clinical Oncology 45 1131-1138.

Li X, Su J, Zhao L, Wu J, Ding X, Fang F, Wu Y, Sun H \& Peng Y 2014 Familial Cushing syndrome due to thymic carcinoids in a multiple endocrine neoplasia type 1 kindred. Endocrine 47 183-190. (doi:10.1007/s12020-013-0141-6)

Lin L, Zhang JH, Panicker LM \& Simonds WF 2008 The parafibromin tumor suppressor protein inhibits cell proliferation by repression of the c-myc proto-oncogene. PNAS 105 17420-17425. (doi:10.1073/ pnas.0710725105)

Lopez CL, Falconi M, Waldmann J, Boninsegna L, Fendrich V, Goretzki PK, Langer P, Kann PH, Partelli S \& Bartsch DK 2013 Partial pancreaticoduodenectomy can provide cure for duodenal gastrinoma associated with multiple endocrine neoplasia type 1 . Annals of Surgery 257 308-314. (doi:10.1097/SLA.0b013e3182536339)

MacFarlane MP, Fraker DL, Alexander HR, Norton JA, Lubensky I \& Jensen RT 1995 Prospective study of surgical resection of duodenal and pancreatic gastrinomas in multiple endocrine neoplasia type 1 . Surgery 118 973-979. (doi:10.1016/S0039-6060(05)80102-3)

Machado MC 2012 Surgical treatment of pancreatic endocrine tumors in multiple endocrine neoplasia type 1. Clinics 67 (Supplement 1) 145-148.

Machens A \& Dralle H 2010 Biomarker-based risk stratification for previously untreated medullary thyroid cancer. Journal of Clinical Endocrinology \& Metabolism 95 2655-2663.

Machens A \& Dralle H 2015 Surgical treatment of medullary thyroid cancer. Recent Results in Cancer Research 204 187-205. (doi:10.1007/978-3-319-22542-5)

Machens A, Brauckhoff M, Holzhausen HJ, Thanh PN, Lehnert H \& Dralle H 2005 Codon-specific development of pheochromocytoma in multiple endocrine neoplasia type 2. Journal of Clinical Endocrinology \& Metabolism 90 3999-4003.

Machens A, Lorenz K \& Dralle H 2013 Peak incidence of pheochromocytoma and primary hyperparathyroidism in multiple endocrine neoplasia 2: need for age-adjusted biochemical screening. Journal of Clinical Endocrinology \& Metabolism 98 E336-E345.

Machens A, Lorenz K \& Dralle H 2014 Utility of serum procalcitonin for screening and risk stratification of medullary thyroid cancer. Journal of Clinical Endocrinology \& Metabolism 99 2986-2994.

Marx SJ, Agarwal SK, Kester MB, Heppner C, Kim YS, Skarulis MC, James LA, Goldsmith PK, Saggar SK, Park SY, et al. 1999 Multiple endocrine neoplasia type 1: clinical and genetic features of the hereditary endocrine neoplasias. Recent Progress in Hormone Research 54 397-438.

Mathews JW, Winchester R, Alsaygh N, Bartlett AM \& Luttrell LM 2015 Hyperparathyroidism-jaw tumor syndrome - an overlooked cause of severe hypercalcemia. American Journal of the Medical Sciences [in press]. (doi:10.1097/MAJ.0000000000000572)

Mehta A, Patel D, Rosenberg A, Boufraqech M, Ellis RJ, Nilubol N, Quezado MM, Marx SJ, Simonds WF \& Kebebew E 2014 
Hyperparathyroidism-jaw tumor syndrome: results of operative management. Surgery 156 1315-1324. (doi:10.1016/ j.surg.2014.08.004)

Miller BS, Rusinko RY \& Fowler L 2008 Synchronous thymoma and thymic carcinoid in a woman with multiple endocrine neoplasia type 1: case report and review. Endocrine Practice 14 713-716.

Morin E, Cheng S, Mete O, Serra S, Araujo PB, Temple S, Cleary S, Gallinger S, Greig PD, McGilvray I, et al. 2013 Hormone profiling, WHO 2010 grading, and AJCC/UICC staging in pancreatic neuroendocrine tumor behavior. Cancer Medicine 2 701-711.

Newey PJ, Bowl MR \& Thakker RV 2009 Parafibromin - functional insights. Journal of Internal Medicine 266 84-98. (doi:10.1111/ j.1365-2796.2009.02107.x)

Newey PJ, Bowl MR, Cranston T \& Thakker RV 2010 Cell division cycle protein 73 homolog (CDC73) mutations in the hyperparathyroidismjaw tumor syndrome (HPT-JT) and parathyroid tumors. Human Mutation 31 295-307. (doi:10.1002/humu.21188)

Niederle B, Sebag F \& Brauckhoff M 2014 Timing and extent of thyroid surgery for gene carriers of hereditary $\mathrm{C}$ cell disease - a consensus statement of the European Society of Endocrine Surgeons (ESES). Langenbeck's Archives of Surgery 399 185-197. (doi:10.1007/s00423013-1139-5)

Nikfarjam M, Warshaw AL, Axelrod L, Deshpande V, Thayer SP, Ferrone CR \& Fernandez-del Castillo C 2008 Improved contemporary surgical management of insulinomas: a 25-year experience at the Massachusetts General Hospital. Annals of Surgery 247 165-172. (doi:10.1097/SLA.0b013e31815792ed)

Norton JA, Venzon DJ, Berna MJ, Alexander HR, Fraker DL, Libutti SK, Marx SJ, Gibril F \& Jensen RT 2008 Prospective study of surgery for primary hyperparathyroidism (HPT) in multiple endocrine neoplasiatype 1 and Zollinger-Ellison syndrome: long-term outcome of a more virulent form of HPT. Annals of Surgery 247 501-510. (doi:10.1097/ SLA.0b013e31815efda5)

Norton JA, Krampitz G \& Jensen RT 2015 Multiple endocrine neoplasia: genetics and clinical management. Surgical Oncology Clinics of North America 24 795-832. (doi:10.1016/j.soc.2015.06.008)

Otake Y, Aoki M, Nakanishi T \& Hashimoto K 2010 Atypical carcinoid of thymus associated with multiple endocrine neoplasia syndrome type 1. General Thoracic and Cardiovascular Surgery 58 534-537. (doi:10.1007/s11748-009-0557-3)

Pichardo-Lowden AR, Manni A, Saunders BD \& Baker MJ 2011 Familial hyperparathyroidism due to a germline mutation of the CDC73 gene: implications for management and age-appropriate testing of relatives at risk. Endocrine Practice 17 602-609. (doi:10.4158/ EP10337.RA)

Powell AC, Alexander HR, Pingpank JF, Steinberg SM, Skarulis M, Bartlett DL, Agarwal S, Cochran C, Seidel G, Fraker D, et al. 2008 The utility of routine transcervical thymectomy for multiple endocrine neoplasia 1-related hyperparathyroidism. Surgery $\mathbf{1 4 4}$ 878-883. (doi:10.1016/j.surg.2008.08.031)

Quayle FJ, Fialkowski EA, Benveniste R \& Moley JF 2007 Pheochromocytoma penetrance varies by RET mutation in MEN 2A. Surgery 142 800-805. (doi:10.1016/j.surg.2007.09.013)

Rajan S, Zaidi G, Agarwal G, Mishra A, Agarwal A, Mishra SK \& Bhatia E 2016 Genotype-phenotype correlation in Indian patients with MEN2-associated pheochromocytoma and comparison of clinico-pathological attributes with apparently sporadic adrenal pheochromocytoma. World Journal of Surgery 40 690-696. (doi:10.1007/s00268-015-3255-6)

Raymond E, Dahan L, Raoul JL, Bang YJ, Borbath I, Lombard-Bohas C, Valle J, Metrakos P, Smith D, Vinik A, et al. 2011 Sunitinib malate for the treatment of pancreatic neuroendocrine tumors. New England Journal of Medicine 364 501-513. (doi:10.1056/NEJMoa1003825)

Recuero Diaz JL, Embun Flor R, Menal Munoz P, Hernandez Ferrandez J, Arraras Martinez MJ \& Rivas de Andres JJ 2013 Thymic carcinoid associated with multiple endocrine neoplasia syndrome type I. Archivos de Bronconeumología 49 122-125.

Rinke A, Muller HH, Schade-Brittinger C, Klose KJ, Barth P, Wied M, Mayer C, Aminossadati B, Pape UF, Blaker M, et al. 2009 Placebo-controlled, double-blind, prospective, randomized study on the effect of octreotide LAR in the control of tumor growth in patients with metastatic neuroendocrine midgut tumors: a report from the PROMID Study Group. Journal of Clinical Oncology 27 4656-4663.

Rowland KJ, Chernock RD \& Moley JF 2013 Pheochromocytoma in an 8 -year-old patient with multiple endocrine neoplasia type $2 \mathrm{~A}$ : implications for screening. Journal of Surgical Oncology 108 203-206. (doi:10.1002/jso.23378)

Sadowski SM, Neychev V, Cottle-Delisle C, Merkel R, Yang LA, Quezado MM, Chang R \& Kebebew E 2014 Detection of insulinoma using (68)Gallium-DOTATATE PET/CT: a case report. Gland Surgery 3 E1-E5.

Sadowski SM, Millo C, Cottle-Delisle C, Merkel R, Yang LA, Herscovitch P, Pacak K, Simonds WF, Marx SJ \& Kebebew E 2015 Results of (68)Gallium-DOTATATE PET/CT scanning in patients with multiple endocrine neoplasia type 1. Journal of the American College of Surgeons 221 509-517. (doi:10.1016/j.jamcollsurg.2015.04.005)

Sakurai A, Yamazaki M, Suzuki S, Fukushima T, Imai T, Kikumori T, Okamoto T, Horiuchi K, Uchino S, Kosugi S, et al. 2012 Clinical features of insulinoma in patients with multiple endocrine neoplasia type 1: analysis of the database of the MEN Consortium of Japan. Endocrine Journal 59 859-866. (doi:10.1507/endocrj.EJ12-0173)

Schantz A \& Castleman B 1973 Parathyroid carcinoma. A study of 70 cases. Cancer 31 600-605. (doi:10.1002/10970142(197303)31:3<600::aid-cncr2820310316>3.0.co;2-0)

Schussheim DH, Skarulis MC, Agarwal SK, Simonds WF, Burns AL, Spiegel AM \& Marx SJ 2001 Multiple endocrine neoplasia type 1: new clinical and basic findings. Trends in Endocrinology \& Metabolism 12 173-178.

Service FJ, McMahon MM, O'Brien PC \& Ballard DJ 1991 Functioning insulinoma - incidence, recurrence, and long-term survival of patients: a 60-year study. Mayo Clinic Proceedings 66 711-719.

Shane E 2001 Clinical review 122: parathyroid carcinoma. Journal of Clinical Endocrinology \& Metabolism 86 485-493.

Sharretts JM \& Simonds WF 2010 Clinical and molecular genetics of parathyroid neoplasms. Best Practice \& Research Clinical Endocrinology \& Metabolism 24 491-502.

Shattuck TM, Valimaki S, Obara T, Gaz RD, Clark OH, Shoback D, Wierman ME, Tojo K, Robbins CM, Carpten JD, et al. 2003 Somatic and germ-line mutations of the HRPT2 gene in sporadic parathyroid carcinoma. New England Journal of Medicine 349 1722-1729. (doi:10.1056/NEJMoa031237)

Shibata Y, Yamazaki M, Takei M, Uchino S, Sakurai A \& Komatsu M 2015 Early-onset, severe, and recurrent primary hyperparathyroidism associated with a novel CDC73 mutation. Endocrine Journal 62 627-632.

Sidhu PS, Talat N, Patel P, Mulholland NJ \& Schulte KM 2011 Ultrasound features of malignancy in the preoperative diagnosis of parathyroid cancer: a retrospective analysis of parathyroid tumours larger than 15 mm. European Radiology 21 1865-1873. (doi:10.1007/ s00330-011-2141-3)

Silverberg SJ, Rubin MR, Faiman C, Peacock M, Shoback DM, Smallridge RC, Schwanauer LE, Olson KA, Klassen P \& Bilezikian JP 2007 Cinacalcet hydrochloride reduces the serum calcium concentration in inoperable parathyroid carcinoma. Journal of Clinical Endocrinology \& Metabolism 92 3803-3808.

Singh Ospina N, Thompson GB, Nichols FC, Cassivi SD\& Young WF Jr 2015 Thymic and bronchial carcinoid tumors in multiple endocrine neoplasia type 1: the Mayo Clinic experience from 1977 to 2013. Hormones and Cancer 6 247-253. (doi:10.1007/s12672-015-0228-z)

Siu WK, Law CY, Lam CW, Mak CM, Wong GW, Ho AY, Ho KY, Loo KT, Chiu SC, Chow LT, et al. 2011 Novel nonsense CDC73 mutations in

Published by Bioscientifica Ltc 
Chinese patients with parathyroid tumors. Familial Cancer 10 695-699. (doi:10.1007/s10689-011-9466-6)

Sriphrapradang C, Sornmayura P, Chanplakorn N, Trachoo O, Sae-Chew P \& Aroonroch R 2014 Fine-needle aspiration cytology of parathyroid carcinoma mimic hurthle cell thyroid neoplasm. Case Reports in Endocrinology 2014680876. (doi:10.1155/2014/680876)

Taieb D, Kebebew E, Castinetti F, Chen CC, Henry JF \& Pacak K 2014 Diagnosis and preoperative imaging of multiple endocrine neoplasia type 2: current status and future directions. Clinical Endocrinology $\mathbf{8 1}$ 317-328. (doi:10.1111/cen.12513)

Takagi J, Otake K, Morishita M, Kato H, Nakao N, Yoshikawa K, Ikeda H, Hirooka Y, Hattori Y, Larsson C, et al. 2006 Multiple endocrine neoplasia type I and Cushing's syndrome due to an aggressive ACTH producing thymic carcinoid. Internal Medicine 45 81-86. (doi:10.2169/internalmedicine.45.1427)

Taye A \& Libutti SK 2015 Diagnosis and management of insulinoma: current best practice and ongoing developments. Research and Reports in Endocrine Disorders 5 125-133. (doi:10.2147/rred.s86565)

Thakker RV, Newey PJ, Walls GV, Bilezikian J, Dralle H, Ebeling PR, Melmed S, Sakurai A, Tonelli F \& Brandi ML 2012 Clinical practice guidelines for multiple endocrine neoplasia type 1 (MEN1). Journal of Clinical Endocrinology \& Metabolism 97 2990-3011. (doi:10.1210/jc.2012-1230)

Thomas de Montpreville V, Ghigna MR, Lacroix L, Besse B, Broet P, Dartevelle P, Fadel E \& Dorfmuller P 2013 Thymic carcinomas: clinicopathologic study of 37 cases from a single institution. Virchows Archiv 462 307-313. (doi:10.1007/s00428-013-1371-y)

Thosani S, Ayala-Ramirez M, Palmer L, Hu MI, Rich T, Gagel RF, Cote G, Waguespack SG, Habra MA \& Jimenez C 2013 The characterization of pheochromocytoma and its impact on overall survival in multiple endocrine neoplasia type 2. Journal of Clinical Endocrinology \& Metabolism 98 E1813-E1819. (doi:10.1210/jc.2013-1653)

Toledo SP, Lourenco DM, Santos MA Jr, Tavares MR, Toledo RA \& Correia-Deur JE 2009 Hypercalcitoninemia is not pathognomonic of medullary thyroid carcinoma. Clinics 64 699-706. (doi:10.1590/ S1807-59322009000700015)

Tonelli F 2014 How to follow up and when to operate asymptomatic pancreatic neuroendocrine tumors in multiple endocrine neoplasia type 1? Journal of Clinical Gastroenterology 48 387-389. (doi:10.1097/ MCG.0000000000000087)

Tonelli F, Giudici F, Nesi G, Batignani G \& Brandi ML 2013 Biliary tree gastrinomas in multiple endocrine neoplasia type 1 syndrome. World Journal of Gastroenterology 19 8312-8320. (doi:10.3748/ wig.v19.i45.8312)
Triponez F, Dosseh D, Goudet P, Cougard P, Bauters C, Murat A, Cadiot G, Niccoli-Sire P, Chayvialle JA, Calender A, et al. 2006 Epidemiology data on 108 MEN 1 patients from the GTE with isolated nonfunctioning tumors of the pancreas. Annals of Surgery 243 265-272. (doi:10.1097/01.sla.0000197715.96762.68)

Truran PP, Johnson SJ, Bliss RD, Lennard TW \& Aspinall SR 2014 Parafibromin, galectin-3, PGP9.5, Ki67, and cyclin D1: using an immunohistochemical panel to aid in the diagnosis of parathyroid cancer. World Journal of Surgery 38 2845-2854. (doi:10.1007/ s00268-014-2700-2)

Vezzosi D, Cardot-Bauters C, Bouscaren N, Lebras M, BertholonGregoire M, Niccoli P, Levy-Bohbot N, Groussin L, Bouchard P, Tabarin A, et al. 2015 Long-term results of the surgical management of insulinoma patients with MEN1: a Groupe d'etude des Tumeurs Endocrines (GTE) retrospective study. European Journal of Endocrinology 172 309-319. (doi:10.1530/EJE-14-0878)

Wei CH \& Harari A 2012 Parathyroid carcinoma: update and guidelines for management. Current Treatment Options in Oncology 13 11-23. (doi:10.1007/s11864-011-0171-3)

Wells SA Jr \& Santoro M 2009 Targeting the RET pathway in thyroid cancer. Clinical Cancer Research 15 7119-7123. (doi:10.1158/ 1078-0432.CCR-08-2742)

Wells SA Jr, Robinson BG, Gagel RF, Dralle H, Fagin JA, Santoro M, Baudin E, Elisei R, Jarzab B, Vasselli JR, et al. 2012 Vandetanib in patients with locally advanced or metastatic medullary thyroid cancer: a randomized, double-blind phase III trial. Journal of Clinical Oncology 30 134-141. (doi:10.1200/JCO.2011.35.5040)

Wells SA Jr, Asa SL, Dralle H, Elisei R, Evans DB, Gagel RF, Lee N, Machens A, Moley JF, Pacini F, et al. 2015 Revised American Thyroid Association guidelines for the management of medullary thyroid carcinoma. Thyroid 25 567-610. (doi:10.1089/thy.2014.0335)

Yao JC, Shah MH, Ito T, Bohas CL, Wolin EM, Van Cutsem E, Hobday TJ, Okusaka T, Capdevila J, de Vries EG, et al. 2011 Everolimus for advanced pancreatic neuroendocrine tumors New England Journal of Medicine 364 514-523. (doi:10.1056/ NEJMoa1009290)

Yates CJ, Newey PJ \& Thakker RV 2015 Challenges and controversies in management of pancreatic neuroendocrine tumours in patients with MEN1. Lancet Diabetes \& Endocrinology 3 895-905. (doi:10.1016/ S2213-8587(15)00043-1)

Zwolak A, Rudzki G, Swirska J, Dudzinska M, Daniluk J \& Tarach J 2015 Catecholamine crisis as a first manifestation of familial bilateral pheochromocytoma caused by RET proto-oncogene mutation in codon C 634R. Endokrynologia Polska 66 462-468. (doi:10.5603/ EP.2015.0056)

Received in final form 18 May 2016

Accepted 20 May 2016

Accepted Preprint published online 20 May 2016
() 2016 Society for Endocrinology Printed in Great Britain
Published by Bioscientifica Ltd 